\title{
BMJ Open Patient safety in inpatient mental health settings: a systematic review
}

\author{
Bethan Thibaut, ${ }^{1}$ Lindsay Helen Dewa (1) , ${ }^{1}$ Sonny Christian Ramtale, ${ }^{1}$ \\ Danielle D'Lima, ${ }^{2}$ Sheila Adam, ${ }^{1}$ Hutan Ashrafian (D) , ${ }^{1}$ Ara Darzi, ${ }^{1}$ \\ Stephanie Archer (1) ${ }^{1,3}$
}

To cite: Thibaut B, Dewa LH, Ramtale SC, et al. Patient safety in inpatient mental health settings: a systematic review. BMJ Open 2019;9:e030230. doi:10.1136/ bmjopen-2019-030230

- Prepublication history and additional material for this paper are available online. To view these files, please visit the journal online (http://dx.doi org/10.1136/bmjopen-2019030230).

BT and LHD are joint first authors.

Received 05 March 2019 Revised 11 October 2019 Accepted 20 November 2019

Check for updates

(c) Author(s) (or their employer(s)) 2019. Re-use permitted under CC BY. Published by BMJ.

${ }^{1} \mathrm{NIHR}$ Imperial Patient Safety Tranlsational Research Centre, Department of Surgery and Cancer, Imperial College London, London, UK

${ }^{2}$ Centre for Behaviour Change, Department of Clinical,

Educational and Health Psychology, University College London, London, UK

${ }^{3}$ Department of Public Health and Primary Care, University of Cambridge, Cambridge, UK

Correspondence to Dr Stephanie Archer; stephanie.archer@imperial. ac.uk

\section{ABSTRACT}

Objectives Patients in inpatient mental health settings face similar risks (eg, medication errors) to those in other areas of healthcare. In addition, some unsafe behaviours associated with serious mental health problems (eg, self-harm), and the measures taken to address these (eg, restraint), may result in further risks to patient safety. The objective of this review is to identify and synthesise the literature on patient safety within inpatient mental health settings using robust systematic methodology.

Design Systematic review and meta-synthesis. Embase, Cumulative Index to Nursing and Allied Health Literature, Health Management Information Consortium, MEDLINE, PsycINF0 and Web of Science were systematically searched from 1999 to 2019. Search terms were related to 'mental health', 'patient safety', 'inpatient setting' and 'research'. Study quality was assessed using the Hawker checklist. Data were extracted and grouped based on study focus and outcome. Safety incidents were metaanalysed where possible using a random-effects model. Results of the 57637 article titles and abstracts, 364 met inclusion criteria. Included publications came from 31 countries and included data from over 150000 participants. Study quality varied and statistical heterogeneity was high. Ten research categories were identified: interpersonal violence, coercive interventions, safety culture, harm to self, safety of the physical environment, medication safety, unauthorised leave, clinical decision making, falls and infection prevention and control.

Conclusions Patient safety in inpatient mental health settings is under-researched in comparison to other nonmental health inpatient settings. Findings demonstrate that inpatient mental health settings pose unique challenges for patient safety, which require investment in research, policy development, and translation into clinical practice.

PROSPERO registration number CRD42016034057.

\section{INTRODUCTION}

Patient safety has been defined as the 'avoidance, prevention and amelioration of adverse outcomes or injuries stemming from the process of healthcare'. ${ }^{1}$ Those receiving care in inpatient mental health settings face similar risks (eg, medication errors) to patients in other areas of healthcare. In addition, some of the unsafe behaviours associated with serious mental health problems

\section{Strengths and limitations of this study}

This is the first review to examine patient safety within inpatient mental health settings that uses robust systematic methodology.

- The use of a robust patient safety taxonomy provides a comprehensive list of all incident types and resulted in a wide coverage of publications in terms of setting, country and population.

- This review only included peer-reviewed studies with primary data.

- The last systematic literature search was conducted on 27 June 2019, meaning that literature published since this date will not have been included.

(eg, self-harm), and the measures taken to address these (eg, restraint), may result in further risks to patient safety. ${ }^{2-6}$ There may also be a tension between maximising patient safety and maintaining patient autonomy. Inpatient services will often include patients who are experiencing high levels of mental distress and are therefore at greatest risk.

While mental health research has focused on components of quality of care, published research lacks focus on the science of patient safety $^{7-9}$; the stigma and discrimination associated with mental health problems may contribute to this relative neglect. ${ }^{7}$ Only two reviews have examined patient safety in a mental health context and described factors that influence patient safety. ${ }^{710}$ These reviews highlighted the complexity of patient safety in mental health, including the importance of wider organisational safety culture. While these reviews offer important insights into this complex topic, only a small number of specific patient safety incidents and concepts were examined. As such, the current breadth and depth of patient safety research in inpatient mental health settings is unknown.

The review presented here is exploratory in nature; building on previous reviews, we aimed to report an overview of the existing research base on patient safety in inpatient 
mental health settings. We also aimed to critically reflect on quality and methods used in included studies in the field. ${ }^{11}$ In addition to our original protocol, ${ }^{11}$ we aimed to collate, describe and construct the main research categories, allowing for an easily accessible reference index.

\section{SEARCH STRATEGY AND SELECTION CRITERIA}

A systematic search was developed in line with the Preferred Reporting Items for Systematic Reviews and Meta-Analyses (PRISMA) guidelines. ${ }^{12}$ The protocol for this systematic review has been published elsewhere. ${ }^{11}$

Six databases were searched: Embase, Cumulative Index to Nursing and Allied Health Literature (CINAHL), Health Management Information Consortium (HMIC), MEDLINE, PsycINFO and Web of Science. The search was originally conducted on 5 April 2016 and then updated on 27 June 2019 using a comprehensive list of search terms $(\mathrm{n}=343)$ related to 'mental health' $(\mathrm{n}=73)$, 'patient safety' $(\mathrm{n}=206)$, 'inpatient setting' $(\mathrm{n}=13)$ and 'research' $(\mathrm{n}=51)$; see online supplementary files 1 and 2 for full search criteria and terms. The search terms included in the 'patient safety' facet were based on the National Reporting and Learning System (NRLS) taxonomy for England and Wales ${ }^{13}$ to ensure all incident types were identified in the search. A Google Scholar search using the main search terms was also conducted; it was originally anticipated that the first 20 pages of Google scholar would need to be screened against criteria, ${ }^{11}$ but screening stopped at five pages as no new publications were retrieved. Similarly, we had anticipated hand-searching references of all included papers within the review. However, due to the large number of papers included in the review, only the reference lists of the two existing systematic reviews were searched for additional references.

Five reviewers (BT, CR, LD, DD and SAr) screened all titles against the inclusion and exclusion criteria, with $10 \%$ independently screened by a second reviewer (split equally between BT, CR, LD, DD and SAr). Full definitions and descriptions of these criteria can be found in online supplementary file 1 and the protocol published elsewhere. ${ }^{11}$ Inclusion and exclusion criteria were developed over several iterative rounds among the research team to ensure consistency between reviewers (online supplementary file 1). Any disagreements between reviewers were resolved through discussion and an overall consensus was obtained. Agreement between reviewers was calculated using Cohen's kappa ${ }^{14}$ which is a widely accepted measure of inter-rater reliability. ${ }^{15} 16$ Full-text papers were assessed for inclusion by two reviewers from the research team (BT and one other from CR, LD and $\mathrm{SAr}$ ); a third reviewer (DD) was consulted if necessary.

Inclusion criteria:

- Population: mental health inpatients;

- Intervention/outcomes: patient safety outcomes;

- Setting: inpatient setting;

- Comparators: no restriction;
- General inclusion criteria: empirical peer-reviewed studies with a clear aim or research question, that used primary data and written up in the English language between 1 January 1999 and 27 June 2019 (in line with the publication of the Institute of Medicine's report 'To Err is Human: Building a Safer Health System'). ${ }^{17}$ Exclusion criteria:

- Population: centres on physical healthcare patients;

- Intervention/outcomes: patient safety was not the central aim, research question or outcome

- Setting: amalgamation of data from inpatient and outpatient settings (where inpatient sample cannot be separated out); primary care, outpatient mental health services, community or social care settings and risk assessment tool reliability/validity checks;

- Comparators: no restrictions;

- General exclusion criteria: secondary data, not in English language, protocols, editorials, commentaries/clinical case reviews/'snapshot' studies of a patient group, book chapters, conference abstracts, audits, dissertations, epidemiological studies and reviews.

\section{QUALITY ASSESSMENT}

Quality assessment was performed to give an overview of the methodological rigour of included studies and to support readers' interpretation of the literature. Publications were not excluded based on poor quality because the review was purposively exploratory and allencompassing. Quality was assessed by four reviewers (BT, CR, LD and SAr) using the tool derived by Hawker et $a l,{ }^{18}$ to allow appropriate assessment of the wide variety of studies included in this review. The checklist by Hawker et al evaluates nine domains: 1) abstract/ title; 2) introduction and aims; 3) method and data; 4) sampling; 5) data analysis; 6) ethics and bias; 7) results; 8) transferability and generalisability and 9) implications and usefulness. For each study, the nine domains were assessed using one of four quality categories: very poor (10 points), poor (20 points), fair (30 points) and good ( 40 points). The scores for each study were then summed and divided by nine to get an average score.

\section{DATA EXTRACTION}

Data were extracted by five reviewers (BT, CR, LD, DD and SAr) using a standardised form that included study design information, participant characteristics, intervention description and patient safety outcomes. Extractions were compared within the research team to ensure reliability. Only published data were extracted; study authors were contacted only for confirmation or information clarity. If the contact attempt was unsuccessful, the article was assessed in its current form.

\section{DATA SYNTHESIS}

Studies were grouped into research categories through consensus. First, four research team members (BT, CR, 
LD and SAr) individually re-read the included full-text publications and assigned each one based on the main topic area (eg, aggression). Second, each assigned topic area was checked by another team member to ensure reliability. Third, topic areas were grouped into broader research categories (eg, interpersonal violence) that best described the patient safety focus for easier navigation of the literature. Finally, these categories and the related subcategories (initially called topic areas) from the previous stage were finalised after group discussion and consensus was reached. This was to ensure mutual exclusivity and appropriate definition (table 1 and online supplementary file 3 ). Where data allowed, meta-analysis was performed applying a random-effects model, specifically calculating pooled prevalence considering both between-study and within-study variances that contributed to study weighting. Pooled values and 95\% CIs were computed and represented on forest plots. Statistical heterogeneity was determined by the $\mathrm{I}^{2}$ statistic, where $<30 \%$ is low, $30 \%-60 \%$ is moderate and $>60 \%$ is high. Analyses were performed using Stata V.15 (StataCorp, College Station, Texas, USA).

\section{PATIENT AND PUBLIC INVOLVEMENT}

Patients and the public were not involved in this study.

\section{RESULTS}

The search resulted in 79672 records (figure 1) and reduced to 57637 after de-duplication. Titles and abstracts were screened and excluded if they did not satisfy inclusion criteria (BT, CR, LD, DD and SAr). Ten per cent were then screened $(n=5763)$ by a second independent reviewer (split equally between BT, CR, LD, DD and SAr), in line with guidance on improving decision making by including more than one person in this process ${ }^{19}$; good agreement was found between pairs of reviewers $(\kappa=0.72)$. A total of 4758 publications were subjected to full-text review (BT, CR, LD and SAr). Two reviewers independently screened the full-text articles against inclusion criteria (BT, CR, LD and SAr). The third reviewer (DD) was consulted 59 times. Substantial agreement was reached $(\kappa=0.64)$. From the full-text review, 4394 publications were excluded. Three hundred and sixty-four publications met the inclusion criteria and data were extracted (online supplementary file 4).

\section{Study characteristics}

Table 1 provides an overview of the study characteristics . The publications spanned 5 continents and 31 countries. The three countries contributing the greatest number of studies were the UK $(n=102)$, the USA $(n=55)$ and Australia $(n=32)$. The included studies collected data from over 150000 participants. Studies included staff $(\mathrm{n}=165 ; 45 \%)$, patients $(\mathrm{n}=120 ; 33 \%)$ and a mixture of staff, patients and/or carers $(n=77 ; 21 \%)$. Only one study focused solely on patient family members $(<1 \%)$. Most studies were quantitative in nature $(\mathrm{n}=192 ; 53 \%)$, just over a third were qualitative $(\mathrm{n}=133 ; 37 \%)$ and a small proportion used mixed methodology $(n=39 ; 11 \%)$. Studies were conducted in a variety of settings comprising: psychiatric inpatient wards/facilities $(\mathrm{n}=266 ; 73 \%)$, forensic inpatient facilities $(\mathrm{n}=50 ; 14 \%)$, long-term care/nursing homes $(n=25 ; 7 \%)$, mixed inpatient settings $(n=20 ; 5 \%)$, a learning disability unit $(\mathrm{n}=1 ;<1 \%)$, a health board $(\mathrm{n}=1$; $<1 \%)$ and a specialised research unit $(\mathrm{n}=1 ;<1 \%)$. More information about the study designs used is included in online supplementary file 4 .

\section{Quality assessment}

Most research was assessed as 'fair' quality ( $\mathrm{n}=251 ; 69 \%)$, $86(24 \%)$ papers were assessed as 'good' quality and 26 $(7 \%)$ were assessed as 'poor' quality. None was assessed as 'very poor' quality. Studies rated as 'poor' mainly did not discuss ethical considerations, potential biases or give sample or setting characteristics. For example, they did not consider recruitment strategies, sample demographics or provide detailed information on the research setting. All 'good' studies provided setting and sampling information to allow for replicability. In addition, 'good' studies provided detail on data analysis justification, more thorough literature reviews to place the study in context and had clear research aims/objectives. Online supplementary file 5 includes a table showing the breakdown of the quality domain scores for each paper.

\section{Synthesis}

Ten research categories were identified: interpersonal violence, coercive interventions, safety culture, harm to self, safety of the physical environment, medication safety, unauthorised leave, clinical decision making, falls and infection prevention and control. Within these categories 46 subcategories were identified (table 1 ).

\section{Interpersonal violence}

Interpersonal violence was the largest category $(n=116$; $32 \%)$. Studies were primarily concerned with the prevalence, management and prevention of violent and aggressive behaviours $(n=75)$. The pooled prevalence for physical violence was $43.2 \%$ (95\% CI 0.37 to 0.49 ) with high heterogeneity $\left(\mathrm{I}^{2} 100.0 \%\right)$ in 20 studies $^{20-39}$ (online supplementary file 6 ). The pooled prevalence for verbal aggression was $57.4 \%$ (95\% CI 0.34 to 0.81 ) with a high heterogeneity $\left(\mathrm{I}^{2} 100.0 \%\right)$ in 10 studies $^{22-24} 262933-3640$ (online supplementary file 6 ).

One study examined the characteristics of aggressive incidents by ward type, ${ }^{41}$ and two studies identified correlates of violence. ${ }^{43}$ One study explored how patients described their aggressive behaviours. ${ }^{44}$ Twentyfour studies evaluated intervention effectiveness (eg, staff training and medication use) to reduce violent and aggressive behaviours, with most finding significant improvements, ${ }^{45-65}$ two reporting negative outcomes ${ }^{66} 67$ and one reporting mixed findings. ${ }^{68}$ The general management of violent and aggressive behaviours was explored 


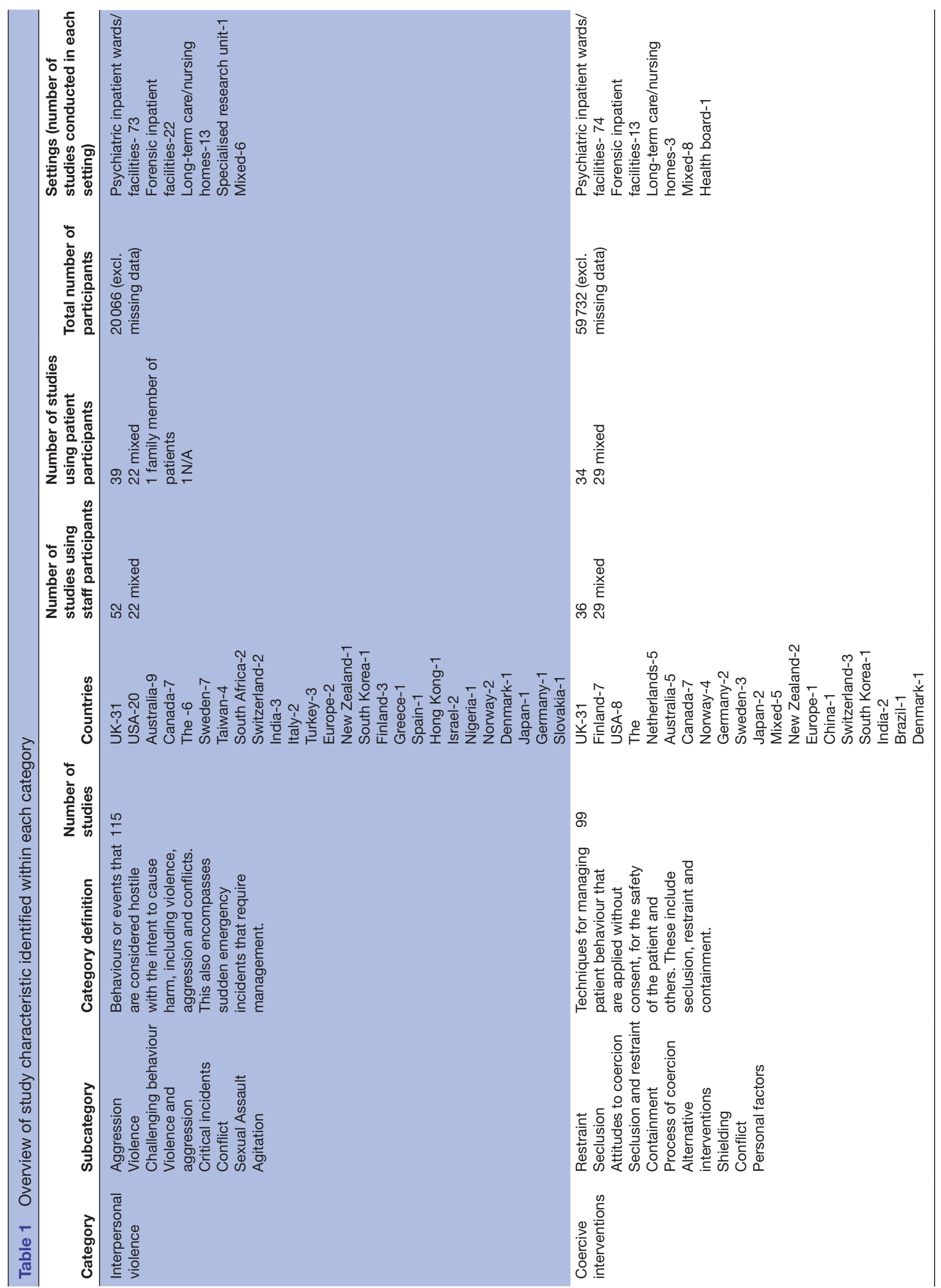




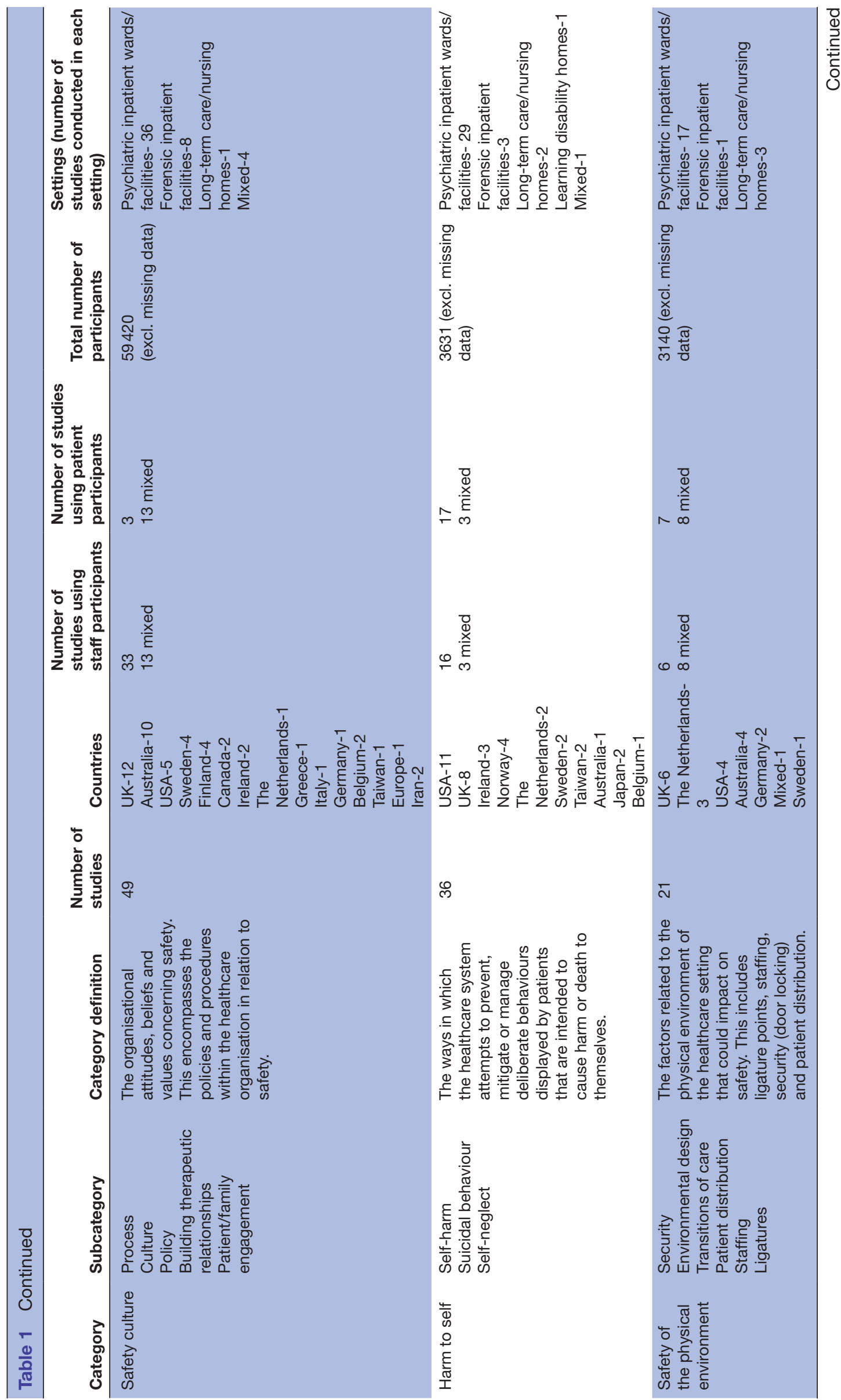




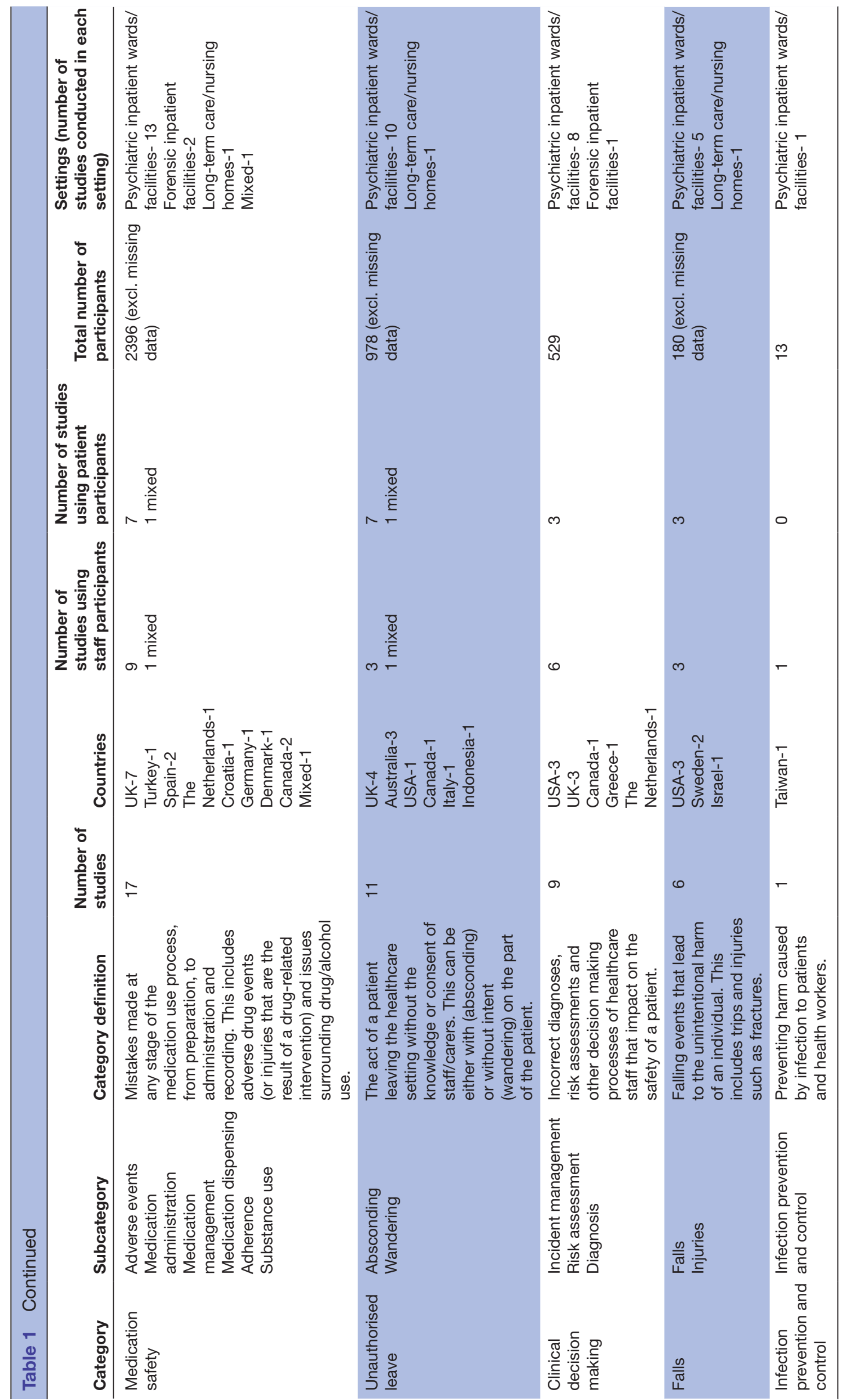

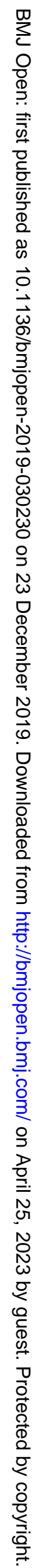




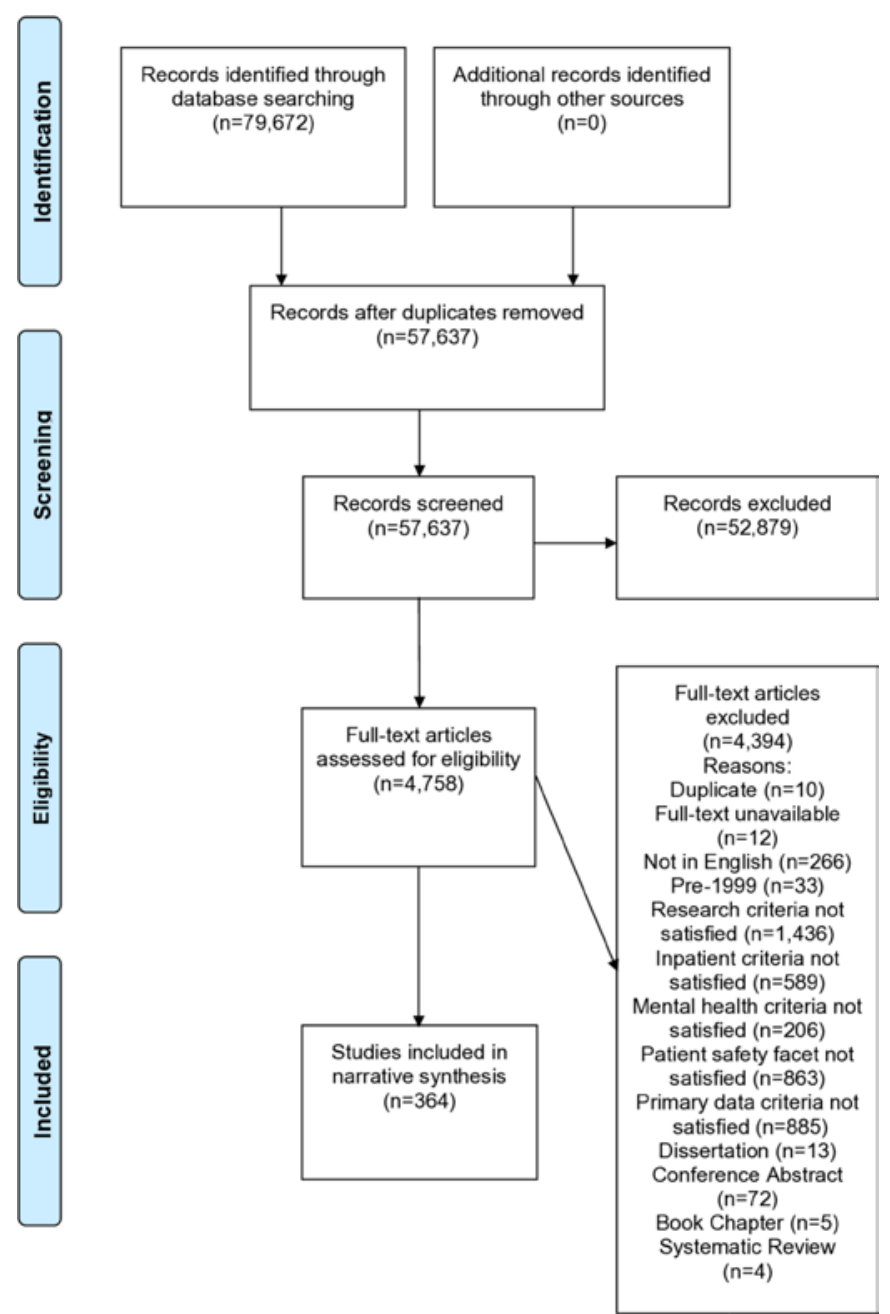

Figure 1 Flow chart of studies.

in 15 studies. $^{22} 25293069-79$ Two studies explored the ways in which treatment can affect violence incidence. ${ }^{31} 80$

Twenty-seven studies explored violent and aggressive incident experiences in staff, ${ }^{81-96}$ patients, ${ }^{97-99}$ mixed groups ${ }^{100-106}$ and patient family members. ${ }^{27}$ Five studies explored the risk factors associated with verbal and physical aggression. ${ }^{35} 37107-109$ Three studies explored mental health nurses' perspectives on the response to violent situations in high secure environments: one on the psychological impact of physical assault on staff, ${ }^{110}$ one on making violence risk assessments in imminent violent situations ${ }^{111}$ and one on the decline of incident reports. ${ }^{112}$ One study explored the link between aggressive behaviour and levels of burnout in staff ${ }^{13}$ and one study looked at the role of social support for staff following a violent incident. ${ }^{32}$

Ten studies ${ }^{114-123}$ examined challenging behaviour and techniques, such as de-escalation and communication strategies, which could be used to manage this; seven studies found techniques that were effective. ${ }^{114-120}$ A further four studies investigated conflict behaviour management techniques employed by staff $^{124-126}$ and patients $^{127}$; techniques used in the two intervention studies were effective in reducing conflict. ${ }^{126127}$ Staff and patient attitudes towards critical incidents were the focus of four qualitative studies ${ }^{128-131}$; a further three studies focused on maintaining the psychological safety of patients who had experienced physical or sexual assault during an inpatient stay ${ }^{132}$ and outside of healthcare. ${ }^{133} 134$ Finally, one study explored an acupressure intervention to reduce agitation, which was found to be effective. ${ }^{135}$

\section{Coercive interventions}

Coercive interventions were the focus of 98 papers $(27 \%)$. Most studies $(n=42)$ reported on restraint and seclusion techniques. The pooled prevalence for coercive interventions was $47.8 \%$ (95\% CI 0.38 to 0.57 ) with high heterogeneity $\left(\mathrm{I}^{2} 100.0 \%\right)$ in 12 studies ${ }^{136-147}$ (online supplementary file 6).

Studies explored staff, ${ }^{148-157}$ patient $^{147}$ 158-165 and mixed groups, ${ }^{166-173}$ views and experiences of seclusion and restraint. Nine studies focused on the processes surrounding seclusion and restraint. ${ }^{136137174-180}$ A further 16 studies evaluated interventions to reduce seclusion and restraint, with 13 finding significant decreases in rates of use, ${ }^{146}$ 181-192 one reporting an increase ${ }^{193}$ and one reporting increased levels of knowledge about the topic area. ${ }^{194}$ Four studies examined prevalence, trends and preventative factors ${ }^{138}{ }^{195-197}$; one found that $45 \%$ of patients were subjected to restraint, ${ }^{138}$ and another found that restraint and seclusion declined over time. ${ }^{197}$ One study explored the context in which seclusion and restraint had taken place. ${ }^{198}$ Two studies found preventative factors of mechanical restraint to be staff education and increased patient involvement. ${ }^{195} 196$ The training of staff in techniques for seclusion and restraint were explored in two studies ${ }^{199} 200$ and one study examined adverse events resulting from restraint and seclusion. ${ }^{201}$ Other studies explored staff and patient views of containment measures, ${ }^{202-205}$ Maori views of initiatives to reduce/ prevent seclusion, ${ }^{206}$ the process of shielding (segregation under staff supervision), ${ }^{207}$ conflict management ${ }^{208}$ and alternative interventions. ${ }^{209}$

Thirty-two studies focused on coercion; one study examined prevalence of coercive measures ${ }^{141}$ and one study explored how the experience of staff might contribute to the use of restrictive practices. ${ }^{210}$ The attitudes of staff, ${ }^{142} 144{ }^{211-222}$ patients ${ }^{145} 223-226$ and mixed groups $^{143} 168$ 227-230 towards coercion were explored in 25 studies, and 5 studies examined the process of coercive interventions ${ }^{139140231232}$ and rules of engagement in caring for aggressive patients. ${ }^{233}$

\section{Safety culture}

Safety culture included studies on processes, culture and policy across 49 papers $(13 \%)$. Eighteen studies concerned safety-related organisational processes. Eleven of these investigated processes of treatment or care that healthcare staff undertake; processes included limit-setting and clothing restrictions, ${ }^{234-240}$ risk assessment ${ }^{241-243}$ and nursing handover. ${ }^{244}$ Two investigated errors and reporting ${ }^{245} 246$ and a further two studies explored staff and patient perceptions of safety when 
involved in treatment processes. ${ }^{247} 248$ Two studies focused on change implementation. ${ }^{249}{ }^{250}$ One study focused on the role of training. ${ }^{251}$ Safety culture was featured in 18 publications relating to the management of serious incidents, ${ }^{252-254}$ stress and burnout, ${ }^{255-257}$ staff $^{258}$ and patient perspectives of safety ${ }^{259-263}$ and communication ${ }^{264}$; there were also three papers that explored safety culture more generally. ${ }^{265-267} \mathrm{~A}$ further two evaluated the TeamSTEPPS (Team Strategies and Tools to Enhance Performance and Patient Safety) programme 268269 and both found significant clinical benefits in reducing seclusion and improving team functioning. One paper looked at the barriers and facilitators to implementing a Safewards intervention. ${ }^{270}$ With regard to policy, eight studies concerned safety policies related to: observation, ${ }^{271} 272$ risk assessment, ${ }^{273} 274$ treatment, ${ }^{275}$ safeguarding, ${ }^{276}$ security ${ }^{277}$ and ergonomic improvement. ${ }^{278}$ Two papers focused on the role of patient and family engagement in safety, ${ }^{279} 280$ and two papers focused on how to build better therapeutic relationships to improve patient safety. ${ }^{281} 282$

\section{Harm to self}

Three subcategories centred on harmful behaviours: self-harm, suicidal behaviour and self-neglect $(n=36$; $10 \%)$. Half of the studies $(n=18)$ focused on self-harm. One paper explored the prevalence of self-harm. ${ }^{283}$ Two studies explored risk factors for self-harm which included use of psychotropic medication. ${ }^{284} 285$ Eight papers explored staff attitudes and experiences of managing self-harm, ${ }^{286-293}$ and three explored patient experiences. ${ }^{294-296}$ Three intervention studies focused on training ${ }^{297}$ therapy ${ }^{298}$ and observation ${ }^{299}$; all reported a reduction in self-harm behaviours and a further intervention focusing on training for staff resulted in positive attitude towards self-harm patients, greater closeness and improved self-efficacy. ${ }^{300}$ Of the 17 papers that centred on suicidal behaviours, five studies investigated the observance of risk factors ${ }^{301-305}$ and three intervention studies found significant reductions in suicide-related behaviours and cognitions. ${ }^{306-308}$ An additional eight papers explored staff, ${ }^{309-312}$ patient ${ }^{313} 314$ and both staff and patient ${ }^{315} 316$ views and attitudes towards suicidal behaviour. One study looked at the acceptability of an intervention to reduce suicide ${ }^{317}$ Finally, one study explored types of self-neglect behaviours in patients with dementia, including functional difficulties, serious hygiene problems and safety risks. $^{318}$

\section{Safety of the physical environment}

The safety of the physical environment category included 21 papers $(6 \%)$. Seven studies investigated security measures (eg, door locking). ${ }^{319-325}$ Five studies investigated the effects of the physical environmental design on the safety of treatment settings. ${ }^{326-330}$ Three studies focused on safety during transitions of care, ${ }^{331-333}$ with most based in dementia care settings. Three studies examined how the location of patients within the hospital setting can impact on safety, focusing on topics such as: privacy, female-only wards and the use of segregated or combined wards/units. ${ }^{334-336}$ The remaining three studies concerned staffing levels ${ }^{337} 338$ and ligature points. ${ }^{339}$

\section{Medication safety}

The medication safety category included 17 publications $(5 \%)$. Five studies focused on adverse events, and examined: antipsychotics side effects, ${ }^{340}$ how best to manage the effect of psychotropics on long QT segments, ${ }^{341}$ antidepressants ${ }^{342}$ and medication error reporting. ${ }^{343} 344$ Three studies investigated errors occurring in broader medication management processes ${ }^{345-347}$ and a further five studies focused on medication administration specifically. ${ }^{348-352}$ The only intervention study aiming to reduce these errors found that a new medication dispensing system did not have any significant impact on patient safety. ${ }^{353}$ Two studies explored staff perceptions of illicit substance use. ${ }^{354} 355$ One further study described the development of a medication adherence intervention for patients who are prescribed mood-stabilising medication for bipolar disorder. ${ }^{356}$

\section{Unauthorised leave}

Unauthorised leave included 11 publications (3\%). Three explored the patient experience of absconding, specifically relating to patient perspectives of treatment and involuntary commitment. ${ }^{357-359}$ One study explored staff perspectives of absconding management techniques, ${ }^{360}$ and two studies evaluated interventions to reduce absconding rates; both were found to be effective. ${ }^{361} 362$ Two studies focused on wandering behaviour in women with dementia, linking wandering to physical environment factors, such as light, sound, crowding ${ }^{363}$ and falls. ${ }^{364}$ The pooled prevalence of wandering behaviour was $50.2 \%$ (95\% CI 0.49 to 0.52 ) with high heterogeneity ( ${ }^{2}$ $78.0 \%$ ) in two studies ${ }^{363} 364$ (online supplementary file 6).

The final three studies examined the consequences ${ }^{365} 366$ and security measures surrounding absconding. ${ }^{367}$

\section{Clinical decision making}

Clinical decision making accounted for $2 \%$ of the included publications $(n=9)$. These publications covered the development of clinical judgements and decisions relating to incident management, risk assessment and diagnosis. Two studies explored the cultural differences considered by clinicians in the diagnosis of AfricanAmerican patients. ${ }^{368} 369$ Clinical decisions on whether to engage in seclusion and/or restraint were explored in five studies ${ }^{370-374}$ and two studies explored the variation in assessment and prediction of violence between staff and settings. 375376

\section{Falls}

Publications on falls formed the second smallest category within the review $(\mathrm{n}=6 ; 1 \%)$. Studies in this category focused on fall prevalence, falls experienced by older psychiatric inpatients with dementia and prevention/ harm reduction techniques. A recurring risk factor for falling was found to be medication use. ${ }^{377-379}$ Two fall 
prevention intervention studies did not identify significant benefits, ${ }^{380} 381$ and one study explored barriers and facilitators to such interventions. ${ }^{382}$

\section{Infection prevention and control}

One paper $(<1 \%)$ focused on staff experiences of infection prevention and control in psychiatric clinical settings. ${ }^{383}$

\section{DISCUSSION \\ Main findings}

This is the first review to examine patient safety within inpatient mental health settings that uses robust systematic methodology. As a result, we have identified ten research categories: interpersonal violence, coercive interventions, safety culture, harm to self, safety of the physical environment, medication safety, unauthorised leave, clinical decision making, falls and infection prevention and control. In addition, we have been able to include a meta-analysis of incidence and prevalence of aggression (verbal and physical), coercive intervention and wandering behaviour as well as providing an easily accessible reference index of literature in the inpatient mental health and patient safety domain. Previous reviews on this topic had focused on collating the literature on a restricted number $(n=8)$ of predefined patient safety incidents (eg, violence and aggression), ${ }^{7}$ or the concept of patient safety in inpatient mental health setting more broadly (eg, organisation management). ${ }^{10}$ As such, the findings presented here offer a contemporary view of the breadth and depth of patient safety research in inpatient mental health settings.

We were concerned to see that only 364 papers were identified as a result of our comprehensive search. Although this can be seen as a large number of publications for a systematic review, it is a relatively small number to cover the care of a wide range of patients in a variety of inpatient mental health settings over a 20 -year period (around 18 papers per year across all countries). While important work not meeting our inclusion criteria (eg, quality improvement initiatives and studies using secondary analysis of data) may have focused on patient safety in mental health, the lack of prospective peer-reviewed publications adds to the ongoing discussion surrounding the disparity in research focusing on patient safety in physical and mental healthcare. ${ }^{384}$ In addition, there was a paucity of high-quality research in the area; just over two-thirds of the studies were considered to be 'fair', and only nine studies included in the meta-analysis were deemed 'good'. 'Poor' studies most frequently did not have clear research aims and objectives, study details were missing (eg, sample(s) and setting(s) used) and they failed to discuss issues related to ethical and researcher bias. Some qualitative studies explored both staff and patients' perspectives, an important aspect of research, particularly when safety in this context is a relatively new area of knowledge. However, there was limited intervention research, particularly randomised controlled trials (RCTs). In the RCTs that were identified, sample sizes were mostly small.

The findings from the review also challenged our expectations in terms of breadth and depth of research. For example, we expected to find many publications on the prevention of suicide within inpatient settings due to the severity of harm. However, only one study that met inclusion criteria discussed suicide in relation to ligature points. ${ }^{339}$ A scoping review also found only this one study, suggesting a consistency of approach. ${ }^{385}$ This indicates that while the prevention of suicide is a well-established aspect of patient safety, it is now reviewed routinely, using pre-existing and secondary data, rather than through empirical research.

We also found little research focusing on the concepts required for system level reform, ${ }^{386}$ which was disappointing seeing as some improvements have been made in physical healthcare. ${ }^{387}$ For example, in line with research in the physical health domain, ${ }^{388} 389$ we were hoping to find several studies exploring how patient and family engagement in care can promote patient safety. ${ }^{390}$ However, only two studies identified in our review had patient/family engagement as their primary focus. ${ }^{279} 280$ Similarly, we were expecting to identify literature investigating the lack of integration between physical and mental healthcare and the impact it has on patient safety. ${ }^{391}$ However, the need to prevent and manage co-existing physical ill health was not identified in the review. This is surprising as patients with serious mental illness are twice as likely to die prematurely and much more likely to develop long-term conditions or become disabled, as those without serious mental illness. ${ }^{392}$ This patient group is also vulnerable to asphyxiation during restraint and rapid tranquilisation. ${ }^{393}$

Research on medication safety in inpatient mental health settings was also limited in this review. This was unexpected considering two-thirds of patients with mental health problems are prescribed medication and are therefore potentially at risk of experiencing a medication safety incident. Research pertaining to falls was also limited, contrasting with patient safety research within the physical health domain that includes a focus on slips, trips and falls. ${ }^{394}$

\section{Strengths and limitations}

We used a robust patient safety taxonomy to provide a comprehensive list of all incident types. This resulted in a wide coverage of publications in terms of setting, country and population. We systematically searched, screened, extracted and appraised data. As a result, our systematic review draws together all relevant literature concerning patient safety within inpatient mental health settings, simultaneously operating as an index resource for clinicians and researchers.

There were several limitations. We used the definition of patient safety given by Vincent ${ }^{1}$ to guide this review. While this is more nuanced than the original Institute 
of Medicine definition of safety "freedom from accidental injury ${ }^{395}$ and is widely accepted within the patient safety movement, it may be that a more suitable definition reflects the specific challenges within the inpatient mental health setting. ${ }^{396}$ This review only included peerreviewed studies with primary data. Therefore, literature using secondary data such as pre-existing datasets and data from internal audits was excluded as it did not fulfil the criteria of being a prospective research study with clear research aims. ${ }^{397}$ For example, data examined by the National Confidential Inquiry into Suicide and Homicide by People with Mental Illness is collected retrospectively from various sites across the country and would have been excluded from this review. ${ }^{398}$ Moreover, non-peerreviewed quality improvement reports have also been excluded. The decision was made to only include peerpreviewed studies with primary data due to (i) the large number of potential publications in this area, (ii) the need to define the scope and focus of the review and (iii) the need for specificity as well as sensitivity. The investigation of patient safety in mental health inpatient settings using secondary data or in non-peer-reviewed formats is an avenue for additional systematic reviews.

The last systematic literature search was conducted on 27 June 2019, meaning that literature published since this date will not have been included. In order to further build on the review published here, a living systematic review (an ongoing updated summary of high-quality research) ${ }^{399}$ would continue to identify relevant literature in this area. In terms of the meta-analysis, there was expected statistical and methodological variability in studies, particularly for physical and verbal aggression. It is possible that this was due to the inclusion of different definitions of aggression, time periods and type of inpatient setting. In relation to the agreement between reviewers (including the use of recommended piloting of inclusion and exclusion criteria within the screening stage) ${ }^{400}$ inter-rater reliability calculations only achieved substantial agreement $(\kappa=0.61-0.80)$ at both the title and full-text screening stages. Although higher kappas have been reported in other systematic reviews, a substantial agreement is classified as more than acceptable. ${ }^{401}$

While the research spanned five continents, the UK, the USA and Australia contributed over $50 \%$ of the included studies, leading to a potential cultural bias in the body of research identified within the review. We recommend that, where possible, future systematic reviews incorporate manuscripts in languages other than English to establish greater insight into the global literature on patient safety in inpatient mental health settings, with a view to limiting any cultural bias. Similarly, while the removal of publications denoting non-inpatient setting restricted the conclusions to the inpatient setting, issues pertaining to this environment are likely to be different to that of community, primary or social care settings. Additionally, studies were excluded before 1999 to coincide with the release of the Institute of Medicine's report 'To Err is Human: Building a Safer
Health System ${ }^{395}$; this may have narrowed the review scope as the historical context was minimised.

\section{Clinical implications and future research}

This review informs academics, clinicians and service providers about the evidence base in the patient safety field within inpatient mental health settings. The findings allow researchers and clinicians to be directed to literature relevant to a given patient safety topic area, a useful starting point when developing practice guidelines. ${ }^{402}$ Similarly, the findings may influence clinical practice, with those implementing interventions or designing service changes being able to easily access the current scientific understanding.

Future research should be informed by patient safety science more broadly and focus on filling the knowledge gaps highlighted in this review, that is, studies that explore (i) systems level improvement, (ii) patient and carer engagement in safety, (iii) suicide prevention across different countries, (iv) the nature of medication safety in inpatient mental health settings and (v) the prevalence and impact of staff to patient violence. These findings support our previous expert consensus study where academic and service user experts agreed that patientdriven research studies were needed. ${ }^{403}$ The limited rigorous research surrounding patient safety within inpatient mental health settings necessitates future studies to: (i) include large inpatient samples relevant to the research design, (ii) perform appropriate intervention testing and (iii) examine safety from different perspectives. It should also focus on high-quality reporting of research, paying particular attention to the area of ethics, sampling and setting characteristics.

\section{CONCLUSION}

This is the first systematic review to comprehensively examine research on patient safety within inpatient mental health settings. It has drawn together the existing literature and shed light on the gaps in knowledge. Inpatient mental health settings may demonstrate unique patient safety challenges and more research is needed to achieve parity with physical health. Addressing this through a strong body of evidence, informed by patient safety science more broadly, will mean that mental healthcare policy makers are in a better position to address safety issues, and implement robust and evidence-based interventions to improve care.

Twitter Lindsay Helen Dewa @dewalindsay

Acknowledgements The authors would like to thank the librarians at St Mary's Library, Imperial College London for their support with the study.

Contributors BT, LD, SCR, SAr and DD contributed to the design, data searches, data extraction, synthesis and writing of the report. HA contributed to the design, data extraction, meta-analysis and writing of the report. SAd and AD contributed to the design and synthesis, as well as writing and critically reviewing the report.

Funding This work is supported by the National Institute for Health Research (NIHR) Imperial Patient Safety Translation Research Centre. Infrastructure support was provided by the NIHR Imperial Biomedical Research Centre. 
Competing interests None declared.

Patient consent for publication Not required.

Provenance and peer review Not commissioned; externally peer reviewed.

Data availability statement All data relevant to the study are included in the article or uploaded as supplementary information.

Open access This is an open access article distributed in accordance with the Creative Commons Attribution 4.0 Unported (CC BY 4.0) license, which permits others to copy, redistribute, remix, transform and build upon this work for any purpose, provided the original work is properly cited, a link to the licence is given, and indication of whether changes were made. See: https://creativecommons.org/ licenses/by/4.0/.

\section{ORCID iDs}

Lindsay Helen Dewa http://orcid.org/0000-0001-8359-8834

Hutan Ashrafian http://orcid.org/0000-0003-1668-0672

Stephanie Archer http://orcid.org/0000-0003-1349-7178

\section{REFERENCES}

1 Vincent C. Patient safety. Edinburgh: Churchill Livingstone, 2006.

2 Brickell TA, McLean C. Emerging issues and challenges for improving patient safety in mental health: a qualitative analysis of expert perspectives. J Patient Saf 2011;7:39-44.

3 Powell J, Geddes J, Deeks J, et al. Suicide in psychiatric hospital in-patients. risk factors and their predictive power. Br J Psychiatry 2000;176:266-72.

4 Roy A, Draper R. Suicide among psychiatric hospital in-patients. Psychol Med 1995;25:199-202.

5 Gray NS, Hill C, McGleish A, et al. Prediction of violence and selfharm in mentally disordered offenders: a prospective study of the efficacy of HCR-20, PCL-R, and psychiatric symptomatology. $J$ Consult Clin Psychol 2003;71:443-51.

6 Goh SE, Salmons PH, Whittington RM. Hospital suicides: are there preventable factors? profile of the psychiatric hospital suicide. $\mathrm{Br} \mathrm{J}$ Psychiatry 1989;154:247-9.

7 Brickell TA, Nicholls TL, Procyshyn RM. Patient safety in mental health. Canadian Patient Safety Institute, 2000.

8 Vincent GM. Psychopathy and violence risk assessment in youth. Child Adolesc Psychiatr Clin N Am 2006;15:407-28.

9 Taylor TL, Killaspy H, Wright C, et al. A systematic review of the International published literature relating to quality of institutional care for people with longer term mental health problems. BMC Psychiatry 2009;9:55.

10 Kanerva A, Lammintakanen J, Kivinen T. Patient safety in psychiatric inpatient care: a literature review. J Psychiatr Ment Health Nurs 2013;20:541-8.

11 D'Lima D, Archer S, Thibaut Bl, et al. A systematic review of patient safety in mental health: a protocol based on the inpatient setting. Syst Rev 2016;5:203.

12 Moher D, Shamseer L, Clarke M, et al. Preferred reporting items for systematic review and meta-analysis protocols (PRISMA-P) 2015 statement. Syst Rev 2015;4:1

13 NHS Improvement. Learning from patient safety incidents, 2014. Available: http://www.nrls.npsa.nhs.uk/patient-safety-data/

14 Cohen J. A coefficient of agreement for nominal scales. Educ Psychol Meas 1960;20:37-46.

15 McHugh ML. Interrater reliability: the kappa statistic. Biochemia Medica 2012;22:276-82.

16 Belur J, Tompson L, Thornton A, et al. Interrater reliability in systematic review methodology: exploring variation in coder decision-making. Soc Med Res 2018.

17 Donaldson MS, Corrigan JM, Kohn LT. To err is human: building a safer health system. 6. National Academies Press, 2000.

18 Hawker S, Payne S, Kerr C, et al. Appraising the evidence: reviewing disparate data systematically. Qual Health Res 2002;12:1284-99.

19 Edwards P, Clarke M, DiGuiseppi C, et al. Identification of randomized controlled trials in systematic reviews: accuracy and reliability of screening records. Stat Med 2002;21:1635-40.

20 Amoo G, Fatoye FO. Aggressive behaviour and mental illness: a study of in-patients at Aro neuropsychiatric Hospital, Abeokuta. Niger J Clin Pract 2010;13:351-5.

21 Boström A-M, Squires JE, Mitchell A, et al. Workplace aggression experienced by frontline staff in dementia care. J Clin Nurs 2012;21:1453-65.
22 Chen W-C, Hwu H-G, Wang J-D. Hospital staff responses to workplace violence in a psychiatric hospital in Taiwan. Int $J$ Occup Environ Health 2009;15:173-9.

23 Daffern M, Mayer M, Martin T. Staff gender ratio and aggression in a forensic psychiatric hospital. Int J Ment Health Nurs 2006;15:93-9.

24 Ilkiw-Lavalle O, Grenyer BFS. Differences between patient and staff perceptions of aggression in mental health units. Psychiat Ser 2003;54:389-93.

25 Jacob P, Seshadri S, Girimaji SC, et al. Clinical characteristics of aggression in children and adolescents admitted to a tertiary care centre. Asian J Psychiatr 2013;6:556-9.

26 Lehmann LS, McCormick RA, Kizer KW. A survey of assaultive behavior in veterans health administration facilities. Psychiatr Serv 1999;50:384-9.

27 Raveendranathan D, Chandra PS, Chaturvedi SK. Violence among psychiatric inpatients: a victim's perspective. East Asian Arch Psychiatry 2012;22:141-5.

28 Ryan EP, Hart VS, Messick DL, et al. A prospective study of assault against staff by youths in a state psychiatric hospital. Psychiatr Serv 2004:55:665-70.

29 Schwartz TL, Park TL. Assaults by patients on psychiatric residents: a survey and training recommendations. Psychiatr Serv 1999:50:381-3.

30 Sukhodolsky DG, Cardona L, Martin A. Characterizing aggressive and noncompliant behaviors in a children's psychiatric inpatient setting. Child Psychiatry Hum Dev 2005;36:177-93.

31 Wystanski M. Assaultive behaviour in psychiatrically hospitalized elderly: a response to psychosocial stimulation and changes in pharmacotherapy. Int J Geriatr Psychiatry 2000;15:582-5.

32 Kelly EL, Fenwick KM, Brekke JS, et al. Sources of social support after patient assault as related to staff well-being. $J$ Interpers Violence 2017;8:088626051773877-79.

33 Niu S-F, Kuo S-F, Tsai H-T, et al. Prevalence of workplace violent episodes experienced by nurses in acute psychiatric settings. PLoS One 2019;14:e0211183.

34 Danivas V, Lepping P, Punitharani S, et al. Observational study of aggressive behaviour and coercion on an Indian acute ward. Asian $J$ Psychiatr 2016;22:150-6.

35 Podubinski T, Lee S, Hollander Y, et al. Patient characteristics associated with aggression in mental health units. Psychiatry Res 2017:250:141-5.

36 van den Bogaard KJHM, Nijman HLI, Palmstierna T, et al. Characteristics of aggressive behavior in people with mild to borderline intellectual disability and co-occurring psychopathology. J Ment Health Res Intellect Disabil 2018;11:124-42.

37 Pekurinen VM, Välimäki M, Virtanen $\mathrm{M}$, et al. Organizational justice and collaboration among nurses as correlates of violent assaults by patients in psychiatric care. Psychiatr Serv 2017;68:490-6.

38 Kelly EL, Fenwick K, Brekke JS, et al. Well-Being and safety among inpatient psychiatric staff: the impact of conflict, assault, and stress reactivity. Adm Policy Ment Health 2016;43:703-16.

39 Bilici R, Sercan M, Izci F. Levels of the staff's exposure to violence at locked psychiatric clinics: a comparison by occupational groups. Issues Ment Health Nurs 2016;37:501-6.

40 Daffern M, Ogloff J, Howells K. Aggression in an Australian forensic psychiatric hospital. J British Forensic Pract 2003;5:18-28.

41 Sato M, Noda T, Sugiyama N, et al. Characteristics of aggression among psychiatric inpatients by ward type in Japan: Using the Staff Observation Aggression Scale - Revised (SOAS-R). Int J Ment Health Nurs 2017;26:602-11.

42 Ben-Zeev D, Scherer EA, Brian RM, et al. Use of multimodal technology to identify digital correlates of violence among inpatients with serious mental illness: a pilot study. Psychiatr Serv 2017;68:1088-92

43 Bowers L, Allan T, Simpson A, et al. Identifying key factors associated with aggression on acute inpatient psychiatric wards. Issues Ment Health Nurs 2009;30:260-71.

44 Selenius H, Leppänen Östman S, Strand S. Self-Harm as a risk factor for inpatient aggression among women admitted to forensic psychiatric care. Nord J Psychiatry 2016;70:554-60.

45 van de Sande R, Nijman HLI, Noorthoorn EO, et al. Aggression and seclusion on acute psychiatric wards: effect of short-term risk assessment. Br J Psychiatry 2011;199:473-8.

46 Park JS, Lee K. Modification of severe violent and aggressive behavior among psychiatric inpatients through the use of a shortterm Token economy. J Korean Acad Nurs 2012;42:1062-9.

47 Needham I, Abderhalden C, Meer R et al. The effectiveness of two interventions in the management of patient violence in acute mental inpatient settings: report on a pilot study. J Psychiatr Ment Health Nurs 2004;11:595-601. 
48 Murphy CJ, Siv AM. A one year study of mode deactivation therapy: adolescent residential patients with conduct and personality disorders. Int J Behav Cogn Ther 2007;3:327-41.

49 McLaughlin S, Bonner G, Mboche C, et al. A pilot study to test an intervention for dealing with verbal aggression. $\mathrm{Br} J$ Nurs 2010;19:489-94.

50 Killick S, Allen D. Training staff in an adolescent inpatient psychiatric unit in positive approaches to managing aggressive and harmful behaviour: does it improve confidence and knowledge? Child Care Prac 2005;11:323-39.

51 Giles GM, Wager J, Fong L, et al. Twenty-month effectiveness of a non-aversive, long-term, low-cost programme for persons with persisting neurobehavioural disability. Brain Injury 2005;19:753-64.

52 Daffern M, Howells K, Hamilton L, et al. The impact of structured risk assessments followed by management recommendations on aggression in patients with personality disorder. J Forens Psychiatry Psychol 2009;20:661-79.

53 C-Y Yip V, Gudjonsson GH, Perkins D, et al. A non-randomised controlled trial of the R\&R2MHP cognitive skills program in high risk male offenders with severe mental illness. BMC Psychiatry 2013;13:267.

54 Lanza M, Ridenour M, Hendricks S, et al. The violence prevention community meeting: a multi-site study. Arch Psychiatr Nurs 2016;30:382-6.

55 Lanza ML, Rierdan J, Forester L, et al. Reducing violence against nurses: the violence prevention community meeting. Issues Ment Health Nurs 2009;30:745-50.

56 Calabro K, MacKey TA, Williams S. Evaluation of training designed to prevent and manage patient violence. Issues Ment Health Nurs 2002;23:3-15.

57 Björkdahl A, Hansebo G, Palmstierna T. The influence of staff training on the violence prevention and management climate in psychiatric inpatient units. J Psychiatr Ment Health Nurs 2013;20:396-404

58 Arguvanli S.Çet al. Effect of aggression management training program on knowledge and attitudes of nurses working at psychiatric clinics/Agresyon yönetimi egitim programinin psikiyatri kliniklerinde çalisan hemsirelerin bilgi ve tutumlarina etkisi. Anadolu Psikiyatri Dergisi 2015;16.

59 Caspi N, Modai I, Barak P, et al. Pindolol augmentation in aggressive schizophrenic patients: a double-blind crossover randomized study. Int Clin Psychopharmacol 2001;16:111-5.

60 Davies BE, Lowe K, Morgan S, et al. An evaluation of the effectiveness of positive behavioural support within a medium secure mental health forensic service. J Forens Psychiatry Psychol 2019;30:38-52.

61 Isaak V, Vashdi D, Bar-Noy D, et al. Enhancing the safety climate and reducing violence against staff in closed hospital wards. Workplace Health Saf 2017;65:409-16.

62 Price O, Baker J, Bee P, et al. Patient perspectives on barriers and enablers to the use and effectiveness of de-escalation techniques for the management of violence and aggression in mental health settings. J Adv Nurs 2018;74:614-25.

63 Hvidhjelm J, Sestoft D, Skovgaard LT, et al. Aggression in psychiatric wards: effect of the use of a structured risk assessment. Issues Ment Health Nurs 2016;37:960-7.

64 Olsson H, Schön U-K. Reducing violence in forensic care - how does it resemble the domains of a recovery-oriented care? J Ment Health 2016;25:506-11.

65 Mistler LA, Ben-Zeev D, Carpenter-Song E, et al. Mobile mindfulness intervention on an acute psychiatric unit: feasibility and acceptability study. JMIR Mental Health 2017:4.

66 Needham I, Abderhalden C, Halfens RJG, et al. The effect of a training course in aggression management on mental health nurses' perceptions of aggression: a cluster randomised controlled trial. Int $J$ Nurs Stud 2005;42:649-55.

67 Sjöström N, Eder DN, Malm U, et al. Violence and its prediction at a psychiatric hospital. Eur Psychiatry 2001;16:459-65.

68 Sival RC, Albronda T, Haffmans PMJ, et al. Is aggressive behaviour influenced by the use of a behaviour rating scale in patients in a psychogeriatric nursing home? Int $J$ Geriatr Psychiatry 2000;15:108-11.

69 Skovdahl K, Kihlgren AL, Kihlgren M. Dementia and aggressiveness: video recorded morning care from different care units. J Clin Nurs 2003; 12:888-98.

70 Stone T, McMillan M, Hazelton M, et al. Wounding words: swearing and verbal aggression in an inpatient setting. Perspect Psychiatr Care 2011:47:194-203.

71 Sutton D, Wilson M, Van Kessel K, et al. Optimizing arousal to manage aggression: a pilot study of sensory modulation. Int J Ment Health Nurs 2013;22:500-11.
72 Lipscomb JA, London M, Chen YM, et al. Safety climate and workplace violence prevention in state-run residential addiction treatment centers. Work 2012;42:47-56.

73 Wright S, Sayer J, Parr A-M, et al. Breakaway and physical restraint techniques in acute psychiatric nursing: results from a national survey of training and practice. J Forens Psychiatry Psychol 2005;16:380-98.

74 Berg J, Kaltiala-Heino R, Välimäki M. Management of aggressive behaviour among adolescents in forensic units: a four-country perspective. J Psychiatr Ment Health Nurs 2011;18:776-85.

75 Biancosino B, Delmonte S, Grassi L, et al. Violent behavior in acute psychiatric inpatient facilities: a national survey in Italy. J Nerv Ment Dis 2009;197:772-82.

76 Caspi E. Aggressive behaviors between residents with dementia in an assisted living residence. Dementia 2015;14:528-46.

77 Chaplin R, McGeorge M, Hinchcliffe G, et al. Aggression on psychiatric inpatient units for older adults and adults of working age. Int J Geriatr Psychiatry 2008;23:874-6.

78 Delaney J, Cleary M, Jordan R, et al. An exploratory investigation into the nursing management of aggression in acute psychiatric settings. J Psychiatr Ment Health Nurs 2001;8:77-84.

79 Meaden A, Hacker D, Spencer K. Acute aggression risk: an early warning signs methodology. The Journal of Forensic Practice 2013;15:21-31.

80 Umut G, Altun Zeren Öztürk, Danıșmant BS, et al. Relationship between treatment adherence, insight and violence among schizophrenia inpatients in a training Hospital sample. Düşünen Adam 2012;25:212-20.

81 Bahareethan M, Shah A. Aggressive behaviour, staff attitude and staff perception of patients on two continuing care psychogeriatric wards. Aging Ment Health 2000;4:66-71.

82 Berg J, Kaltiala-Heino R, Löyttyniemi V, et al. Staff's perception of adolescent aggressive behaviour in four European forensic units: a qualitative interview study. Nord J Psychiatry 2013;67:124-31.

83 Stevenson KN, Jack SM, O'Mara L, et al. Registered nurses' experiences of patient violence on acute care psychiatric inpatient units: an interpretive descriptive study. BMC Nurs 2015;14:35.

84 Spokes K, Bond K, Lowe T, et al. HOVIS - The Hertfordshire/ Oxfordshire Violent Incident Study. J Psychiatr Ment Health Nurs 2002;9:199-209.

85 Zuzelo PR, Curran SS, Zeserman MA. Registered nurses' and behavior health associates' responses to violent inpatient interactions on behavioral health units. J Am Psychiatr Nurses Assoc 2012;18:112-26.

86 Camuccio CA, CHAMBERS M, VÄLIMÄKI M, et al. Managing distressed and disturbed patients: the thoughts and feelings experienced by Italian nurses. J Psychiatr Ment Health Nurs 2012;19:807-15.

87 McCann TV, Baird J, Muir-Cochrane E. Factors influencing clinicians' attitudes about aggression in Australian acute old age psychiatry inpatient units: a cross sectional survey design. Issues Ment Health Nurs 2014;35:542-50.

88 Tema TR, Poggenpoel M, Myburgh CPH. Experiences of psychiatric nurses exposed to hostility from patients in a forensic ward. J Nurs Manag 2011;19:915-24.

89 Nijman $\mathrm{H}$, Bowers L, Oud N, et al. Psychiatric nurses' experiences with inpatient aggression. Aggress Behav 2005;31:217-27.

90 Chen Wen-Ching, Wang Jung-Der, Lew-Ting Chih-Yin, et al. Workplace violence on workers caring for Long-term institutionalized schizophrenic patients in Taiwan. $J$ Occup Health 2007;49:311-6.

91 Cutcliffe JR. Qualified nurses' lived experience of violence perpetrated by individuals suffering from enduring mental health problems: a hermeneutic study. Int J Nurs Stud 1999;36:105-16.

92 Evans RE, Petter S. Identifying mitigating and challenging beliefs in dealing with threatening patients: an analysis of experiences of clinicians working in a psychiatric intensive care unit. Journal of Psychiatric Intensive Care 2012;8:113-9.

93 Lantta T, Daffern M, Kontio R, et al. Implementing the dynamic appraisal of situational aggression in mental health units. Clinical Nurse Specialist 2015;29:230-43.

94 Tomágová $M$, Bóriková I, Lepiešová $M$, et al. NURSES EXPERIENCE AND ATTITUDES TOWARDS INPATIENT AGGRESSION ON PSYCHIATRIC WARDS. CEJNM 2016;7:462-9.

95 Hylén U, Engström I, Engström K, et al. Providing good care in the shadow of violence - an interview study with nursing staff and ward managers in psychiatric inpatient care in Sweden. Issues Ment Health Nurs 2019:40:148-57.

96 Lantta T, Anttila M, Kontio R, et al. Violent events, ward climate and ideas for violence prevention among nurses in psychiatric wards: a focus group study. Int J Ment Health Syst 2016;10. 
97 Meehan T, McINTOSH W, Bergen H. Aggressive behaviour in the high-secure forensic setting: the perceptions of patients. J Psychiatr Ment Health Nurs 2006;13:19-25.

98 Olsson $\mathrm{H}$, Audulv Åsa, Strand $\mathrm{S}$, et al. Reducing or increasing violence in forensic care: a qualitative study of inpatient experiences. Arch Psychiatr Nurs 2015;29:393-400.

99 Van Wijk E, Traut A, Julie H. Environmental and nursing-staff factors contributing to aggressive and violent behaviour of patients in mental health facilities. Curationis 2014;37:01-8.

100 Daffern M. Assessing the functions of aggression in psychiatric inpatients. Behav Anal Today 2007;8:43-51.

101 Duxbury J, Whittington R. Causes and management of patient aggression and violence: staff and patient perspectives. J Adv Nurs 2005;50:469-78.

102 Janicki N. Prosecuting inpatient violence: perceptions of staff, patients and others in a women's enhanced medium secure service. The British Journal of Forensic Practice 2009;11:27-38.

103 Lawn S, Pols R. Nicotine withdrawal: pathway to aggression and assault in the locked psychiatric ward? Australasian Psychiatry 2003:11:199-203.

104 Nolan KA, Shope CB, Citrome L, et al. Staff and patient views of the reasons for aggressive incidents: a prospective, incident-based study. Psychiatr Q 2009;80:167-72.

105 Dickens G, Piccirillo M, Alderman N. Causes and management of aggression and violence in a forensic mental health service: perspectives of nurses and patients. Int $J$ Ment Health Nurs 2013;22:532-44.

106 Wright KM, Duxbury JA, Baker A, et al. A qualitative study into the attitudes of patients and staff towards violence and aggression in a high security Hospital. J Psychiatr Ment Health Nurs 2014;21:184-8.

107 Lamanna D, Ninkovic D, Vijayaratnam V, et al. Aggression in psychiatric hospitalizations: a qualitative study of patient and provider perspectives. J Ment Health 2016;25:536-42.

108 Paschali M, Kamp D, Reichmann C, et al. A systematic evaluation of impulsive-aggressive behavior in psychogeriatric inpatients using the staff observation aggression scale-revision (SOAS-R). Int Psychogeriatr 2018;30:61-8.

109 Almvik R, Rasmussen K, Woods P. Challenging behaviour in the elderly - monitoring violent incidents. Int J Geriatr Psychiatry 2006;21:368-74.

110 Reininghaus U, Craig T, Gournay K, et al. The High Secure Psychiatric Hospitals' Nursing Staff Stress Survey 3: Identifying stress resistance resources in the stress process of physical assault. Pers Individ Dif 2007:42:397-408.

111 Trenoweth S. Perceiving risk in dangerous situations: risks of violence among mental health inpatients. J Adv Nurs 2003;42:278-87.

112 DE Niet GJ, Hutschemaekers GJM, Lendemeijer BHHG. Is the reducing effect of the staff observation aggression scale owing to a learning effect? an explorative study. J Psychiatr Ment Health Nurs 2005;12:687-94.

113 de Looff P, Nijman H, Didden R, et al. Burnout symptoms in forensic psychiatric nurses and their associations with personality, emotiona intelligence and client aggression: a cross-sectional study. $J$ Psychiatr Ment Health Nurs 2018;25:506-16.

114 Bharwani G, Parikh PJ, Lawhorne LW, et al. Individualized behavior management program for Alzheimer's/dementia residents using behavior-based ergonomic therapies. Am J Alzheimers Dis Other Demen 2012;27:188-95.

115 Carlson GA, Potegal M, Margulies D, et al. Liquid risperidone in the treatment of rages in psychiatrically hospitalized children with possible bipolar disorder. Bipolar Disord 2010;12:205-12.

116 Chan S, Fung MY, Tong CW, et al. The clinical effectiveness of a multisensory therapy on clients with developmental disability. Res Dev Disabil 2005;26:131-42.

117 DeYoung S, Just G, Harrison R. Decreasing aggressive, agitated, or disruptive behavior: participation in a behavior management unit. $J$ Gerontol Nurs 2002;28:22-31.

118 Higueras Aet al. Effects of a humor-centered activity on disruptive behavior in patients in a general Hospital psychiatric ward. International Journal of Clinical and Health Psychology 2006;6:53-64

119 Speziale J, Black E, Coatsworth-Puspoky R, et al. Moving forward: Evaluating a curriculum for managing responsive behaviors in a geriatric psychiatry inpatient population. Gerontologist 2009;49): :570-6.10.1093/geront/gnp069

120 Zwijsen SA, Smalbrugge M, Eefsting JA, et al. Coming to grips with challenging behavior: a cluster randomized controlled trial on the effects of a multidisciplinary care program for challenging behavior in dementia. J Am Med Dir Assoc 2014;15:531.e1-531.e10. : p. e1531.
121 Bennett R, Ramakrishna V, Maganty D. Management of disturbed behaviour in a psychiatric intensive care unit: views of staff on options for intervention. Journal of Psychiatric Intensive Care 2011;7:85-9.

122 Foley KL, Sudha S, Sloane PD, et al. Staff perceptions of successful management of severe behavioral problems in dementia special care units. Dementia 2003;2:105-24.

123 Hallett N, Dickens GL. De-escalation: a survey of clinical staff in a secure mental health inpatient service. Int $J$ Ment Health Nurs 2015;24:324-33.

124 Bowers L. Association between staff factors and levels of conflict and containment on acute psychiatric wards in England. Psychiatric Services 2009;60:231-9.

125 Lowe T, Wellman N, Taylor R. Limit-setting and decision-making in the management of aggression. J Adv Nurs 2003;41:154-61.

126 Ireland JL, Sebalo I, McNeill K, et al. Impacting on factors promoting intra-group aggression in secure psychiatric settings. Heliyon 2019;5.

127 Quirk A, Lelliott P, Seale C. Risk management by patients on psychiatric wards in London: an ethnographic study. Health Risk Soc 2005;7:85-91.

128 Ireland CA, Halpin L, Sullivan C. Critical incidents in a forensic psychiatric population: an exploratory study of motivational factors. $J$ Forens Psychiatry Psychol 2014;25:714-32.

129 Jeffs L, Rose D, Macrae C, et al. What near misses tell us about risk and safety in mental health care. J Psychiatr Ment Health Nurs 2012;19:430-7.

130 Koukia E, Mangoulia P, Stathopoulos T, et al. Greek mental health nurses' practices and attitudes in the management of acute cases. Issues Ment Health Nurs 2013;34:192-7.

131 Terkelsen TB, Larsen IB. Fear, danger and aggression in a Norwegian locked psychiatric ward: dialogue and ethics of care as contributions to combating difficult situations. Nursing Ethics 2016;23:308-17.

132 Cole M, Baldwin D, Thomas P. Sexual assault on wards: staff actions and reactions. Int J Psychiatry Clin Pract 2003;7:239-42.

133 Phillips L. Reflections on the education and training of mental health staff who work with women who have been sexually abused in childhood. J Psychiatr Ment Health Nurs 2011;18:696-705.

134 Gallop R, Engels S, DiNunzio R, et al. Abused women's concerns about safety and the therapeutic environment during psychiatric hospitalization. Can J Nurs Res 1999;31:53-70.

135 Yang M-H, Wu S-C, Lin J-G, et al. The efficacy of acupressure for decreasing agitated behaviour in dementia: a pilot study. J Clin Nurs 2007;16:308-15

136 Cormac I, Russell I, Ferriter M. Review of seclusion policies in high secure hospitals and medium secure units in England, Scotland and Wales. J Psychiatr Ment Health Nurs 2005;12:380-2.

137 Georgieva I, Mulder CL, Noorthoorn E. Reducing seclusion through involuntary medication: a randomized clinical trial. Psychiatry Res 2013:205:48-53.

138 Kirkevold Øyvind, Engedal K. Prevalence of patients subjected to constraint in Norwegian nursing homes. Scand J Caring Sci 2004;18:281-6.

139 Raboch J, Kalisová L, Nawka A, et al. Use of coercive measures during involuntary hospitalization: findings from ten European countries. Psychiatr Serv 2010;61:1012-7.

140 Steinert T, Martin V, Baur M, et al. Diagnosis-Related frequency of compulsory measures in 10 German psychiatric hospitals and correlates with Hospital characteristics. Soc Psychiatry Psychiatr Epidemiol 2007:42:140-5.

141 Gowda GS, Lepping P, Noorthoorn EO, et al. Restraint prevalence and perceived coercion among psychiatric inpatients from South India: a prospective study. Asian J Psychiatr 2018;36:10-16.

142 Gowda GS, Lepping P, Ray S, et al. Clinician attitude and perspective on the use of coercive measures in clinical practice from tertiary care mental health establishment - A cross-sectional study. Indian J Psychiatry 2019;61:151-5.

143 Hotzy F, Jaeger M, Buehler E, et al. Attitudinal variance among patients, next of kin and health care professionals towards the use of containment measures in three psychiatric hospitals in Switzerland. BMC Psychiatry 2019;19:128.

144 Vedana KGG, da Silva DM, Ventura CAA, et al. Physical and mechanical restraint in psychiatric units: perceptions and experiences of nursing staff. Arch Psychiatr Nurs 2018:32:367-72.

145 Krieger E, Moritz S, Weil R, et al. Patients' attitudes towards and acceptance of coercion in psychiatry. Psychiatry Res 2018;260:478-85.

146 Reynolds EK, Grados MA, Praglowski N, et al. Use of modified positive behavioral interventions and supports in a psychiatric 
inpatient unit for high-risk youths. Psychiatric Services 2016;67:570-3.

147 Brady NS, Spittal MJ, Brophy LM, et al. Patients' Experiences of Restrictive Interventions in Australia: Findings From the 2010 Australian Survey of Psychosis. Psychiatric Services 2017;68:966-9.

148 Bigwood S, Crowe M. 'It's part of the job, but it spoils the job': A phenomenological study of physical restraint. Int J Ment Health Nurs 2008;17:215-22.

149 Lee S, GRAY R, GOURNAY K, et al. Views of nursing staff on the use of physical restraint. $J$ Psychiatr Ment Health Nurs 2003;10:425-30.

150 Perkins E, Prosser H, Riley D, et al. Physical restraint in a therapeutic setting; a necessary evil? Int J Law Psychiatry 2012;35:43-9.

151 Sequeira $\mathrm{H}$, Halstead S. The psychological effects on nursing staff of administering physical restraint in a secure psychiatric hospital: 'When I go home, it's then that I think about it'. The British Journal of Forensic Practice 2004;6:3-15.

152 Exworthy T, Mohan D, Hindley N, et al. Seclusion: punitive or protective? The Journal of Forensic Psychiatry 2001;12:423-33.

153 Kuosmanen L, Makkonen P, Lehtila H, et al. Seclusion experienced by mental health professionals. J Psychiatr Ment Health Nurs 2015;22:333-6.

154 Muir-Cochrane EC, Baird J, McCann T. Nurses' experiences of restraint and seclusion use in short-stay acute old age psychiatry inpatient units: a qualitative study. J Psychiatr Ment Health Nurs 2015;22:109-15.

155 Duxbury J, Thomson G, Scholes A, et al. Staff experiences and understandings of the restrain yourself initiative to minimize the use of physical restraint on mental health wards. Int J Ment Health Nurs 2019:28:845-56.

156 Nielsen LD, Gildberg FA, Bech P, et al. Forensic mental health clinician's experiences with and assessment of alliance regarding the patient's readiness to be released from mechanical restraint. Int $J$ Ment Health Nurs 2018;27:116-25.

157 Kontio R, Välimäki M, Putkonen H, et al. Patient restrictions: are there ethical alternatives to seclusion and restraint? Nurs Ethics 2010;17:65-76.

158 Chien W-T, Chan CWH, Lam L-W, et al. Psychiatric inpatients' perceptions of positive and negative aspects of physical restraint. Patient Educ Couns 2005:59:80-6.

159 Knowles SF, Hearne J, Smith I. Physical restraint and the therapeutic relationship. J Forens Psychiatry Psychol 2015;26:461-75.

160 Ezeobele IE, Malecha AT, Mock A, et al. Patients' lived seclusion experience in acute psychiatric hospital in the United States: a qualitative study. J Psychiatr Ment Health Nurs 2014;21:303-12.

161 Faschingbauer KM, Peden-McAlpine C, Tempel W. Use of Seclusion: finding the voice of the patient to influence practice. $J$ Psychosoc Nurs Ment Health Serv 2013;51:32-8.

162 Holmes D, Kennedy SL, Perron A. The mentally ill and social exclusion: a critical examination of the use of seclusion from the patient's perspective. Issues Ment Health Nurs 2004;25:559-78.

163 Bergk J, Einsiedler B, Flammer E, et al. A randomized controlled comparison of seclusion and mechanical restraint in inpatient settings. Psychiatr Serv 2011;62:1310-7.

164 Kontio R, Joffe G, Putkonen H, et al. Seclusion and restraint in psychiatry: patients' experiences and practical suggestions on how to improve practices and use alternatives. Perspect Psychiatr Care 2012;48:16-24.

165 Larue C, Dumais A, Boyer R, et al. The experience of seclusion and restraint in psychiatric settings: perspectives of patients. Issues Ment Health Nurs 2013;34:317-24.

166 Bonner G, Lowe T, Rawcliffe D, et al. Trauma for all: a pilot study of the subjective experience of physical restraint for mental health inpatients and staff in the UK. J Psychiatr Ment Health Nurs 2002;9:465-73

167 Fish R, Hatton C. Gendered experiences of physical restraint on locked wards for women. Disabil Soc 2017;32:790-809.

168 Wilson C, Rouse L, Rae S, et al. Mental health inpatients' and staff members' suggestions for reducing physical restraint: A qualitative study. J Psychiatr Ment Health Nurs 2018;25:188-200.

169 Fish R. 'Behind This Wall' - Experiences of Seclusion on Locked Wards for Women. Scandinavian Journal of Disability Research 2018;20:139-51.

170 Gowda GS, Kumar CN, Ray S, et al. Caregivers' attitude and perspective on coercion and restraint practices on psychiatric inpatients from South India. J Neurosci Rural Pract 2019;10:261-6.

171 Larue C, Goulet M-H, Prevost M-J, et al. Identification and analysis of factors contributing to the reduction in Seclusion and restraint for a population with intellectual disability. Journal of Applied Research in Intellectual Disabilities 2018;31:e212-22.

172 Wilson C, Rouse L, Rae S, et al. Is restraint a 'necessary evil' in mental health care? Mental health inpatients' and staff members' experience of physical restraint. Int J Ment Health Nurs 2017;26:500-12.

173 Holmes D, Murray SJ, Knack N. Experiencing Seclusion in a forensic psychiatric setting: a phenomenological study. J Forensic Nurs 2015;11:200-13.

174 Bonner G, Wellman N. Postincident review of aggression and violence in mental health settings. J Psychosoc Nurs Ment Health Serv 2010;48:35-40.

175 Bowers L, Van Der Merwe M, Paterson B, et al. Manual restraint and shows of force: the City-128 study. Int J Ment Health Nurs 2012;21:30-40.

176 Tompsett CJ, Domoff S, Boxer P. Prediction of restraints among youth in a psychiatric Hospital: application of translational action research. J Clin Psychol 2011;67:368-82.

177 Boumans CE, Egger JIM, Souren PM, et al. Nurses' decision on seclusion: patient characteristics, contextual factors and reflexivity in teams. J Psychiatr Ment Health Nurs 2012;19:264-70.

178 Mason T, Whitehead E. Some specific problems of secluding female patients. Med Sci Law 2001;41:315-24.

179 Ryan R, Happell B. Learning from experience: using action research to discover consumer needs in post-seclusion Debriefing. Int $J$ Ment Health Nurs 2009;18:100-7.

180 Whitecross F, Seeary A, Lee S. Measuring the impacts of seclusion on psychiatry inpatients and the effectiveness of a pilot singlesession post-seclusion counselling intervention. Int J Ment Health Nurs 2013;22:512-21.

181 Bleijlevens MHC, Gulpers MJM, Capezuti E, et al. Process evaluation of a multicomponent intervention program (EXBELT) to reduce belt restraints in nursing homes. J Am Med Dir Assoc 2013;14:599-604.

182 Pellfolk TJ-E, Gustafson Y, Bucht G, et al. Effects of a restraint minimization program on staff knowledge, attitudes, and practice: a cluster randomized trial. J Am Geriatr Soc 2010;58:62-9.

183 Schreiner GM, Crafton CG, Sevin JA. Decreasing the use of mechanical restraints and locked seclusion. Adm Policy Ment Health 2004;31:449-63.

184 Ching H, Daffern M, Martin T, et al. Reducing the use of seclusion in a forensic psychiatric Hospital: assessing the impact on aggression, therapeutic climate and staff confidence. J Forens Psychiatry Psychol 2010;21:737-60.

185 Long CG, West R, Afford M, et al. Reducing the use of seclusion in a secure service for women. Journal of Psychiatric Intensive Care 2015;11:84-94.

186 Smith S, Jones J. Use of a sensory room on an intensive care unit. $J$ Psychosoc Nurs Ment Health Serv 2014;52:22-30.

187 Espinosa L, Harris B, Frank J, et al. Milieu improvement in psychiatry using evidence-based practices: the long and winding road of culture change. Arch Psychiatr Nurs 2015;29:202-7.

188 Kontio R, LAHTI M, PITKÄNEN A, et al. Impact of eLearning course on nurses' professional competence in seclusion and restraint practices: a randomized controlled study (ISRCTN32869544). $J$ Psychiatr Ment Health Nurs 2011;18:813-21.

189 Goulet M-H, Larue C, Lemieux AJ. A pilot study of "post-seclusion and/or restraint review" intervention with patients and staff in a mental health setting. Perspect Psychiatr Care 2018;54:212-20.

190 Blair EW, Woolley S, Szarek BL, et al. Reduction of Seclusion and restraint in an inpatient psychiatric setting: a pilot study. Psychiatr $Q$ 2017;88:1-7.

191 Newman J, Paun O, Fogg L. Effects of a staff training intervention on Seclusion rates on an adult inpatient psychiatric unit. $J$ Psychosoc Nurs Ment Health Serv 2018;56:23-30.

192 Elzubeir K, Dye S. Can amount and duration of seclusion be reduced in psychiatric intensive care units by agreeing smart goals with patients? Journal of Psychiatric Intensive Care 2017:13:109-16.

193 Huizing AR, Hamers JPH, Gulpers MJM, et al. Short-Term effects of an educational intervention on physical restraint use: a cluster randomized trial. BMC Geriatr 2006;6:17.

194 Abdel-Hussein NH, Mohamed SH. Effectiveaness of an Educational Program on Nurses' Knowledge toward Restraint and Seclusion for inpatients at Psychiatric Teaching Hospitals. Indian J Public Health Res Dev 2018;9:1175-80.

195 Bak J, Zoffmann V, Sestoft DM, et al. Mechanical restraint in psychiatry: preventive factors in theory and practice. A Danish-Norwegian association study. Perspect Psychiatr Care 2014;50:155-66. 
196 Bak J, Zoffmann V, Sestoft DM, et al. Comparing the effect of nonmedical mechanical restraint preventive factors between psychiatric units in Denmark and Norway. Nord J Psychiatry 2015;69:1715-25.

197 Keski-Valkama A, Sailas E, Eronen M, et al. A 15-year national follow-up: legislation is not enough to reduce the use of seclusion and restraint. Soc Psychiatry Psychiatr Epidemiol 2007:42:747-52.

198 Goulet M-H, Larue C, Dumais A. Evaluation of seclusion and restraint reduction programs in mental health: a systematic review. Aggress Violent Behav 2017;34:139-46.

199 Lee SW, Sayer J, Parr A-M, et al. Soo, physical restraint training for nurses in English and Welsh psychiatric intensive care and regional secure units. J Ment Health 2001;10:151-62.

200 Kontio R, Välimäki M, Putkonen H, et al. Nurses' and physicians' educational needs in seclusion and restraint practices. Perspect Psychiatr Care 2009;45:198-207.

201 Hatta K, Shibata N, Ota T, et al. Association between physical restraint and drug-induced liver injury. Neuropsychobiology 2007;56:180-4.

202 Bowers L, Alexander J, Simpson A, et al. Student psychiatric nurses' approval of containment measures: Relationship to perception of aggression and attitudes to personality disorder. Int $J$ Nurs Stud 2007;44:349-56.

203 Braham LG, Heasley JF, Akiens S. An evaluation of night confinement in a high secure Hospital. Mental Healt Rev $J$ 2013;18:21-31

204 Chu S, McNeill K, Wright KM, et al. The impact of a night confinement policy on patients in a UK high secure inpatient mental health service. The Jnl of Forensic Practice 2015;17:21-30.

205 Hottinen A, VÄLIMÄKI M, SAILAS E, et al. Attitudes towards different containment measures: a questionnaire survey in Finnish adolescent psychiatry. J Psychiatr Ment Health Nurs 2012;19:521-7.

206 Wharewera-Mika JP, Cooper EP, Wiki NRN, et al. Strategies to reduce the use of seclusion with tāngata whai I te ora (Māori mental health service users). Int J Ment Health Nurs 2016;25:258-65.

207 Haugom EW, Granerud A. Shielding in mental health hospitals: description and assessment by staff. SAGE Open 2016;6.

208 Papadopoulos C, Bowers L, Quirk A, et al. Events preceding changes in conflict and containment rates on acute psychiatric wards. Psychiatr Serv 2012;63:40-7.

209 Ejneborn Looi G-M, Engström Åsa, Sävenstedt S. A self-destructive care: self-reports of people who experienced coercive measures and their suggestions for alternatives. Issues Ment Health Nurs 2015;36:96-103.

210 Barr L, Wynaden D, Heslop K. Promoting positive and safe care in forensic mental health inpatient settings: evaluating critical factors that assist nurses to reduce the use of restrictive practices. Int $J$ Ment Health Nurs 2019;28:888

211 Bak J, Aggernæs H. Coercion within Danish psychiatry compared with 10 other European countries. Nord J Psychiatry 2012;66:297-302

212 Jaeger M, Ketteler D, Rabenschlag F, et al. Informal coercion in acute inpatient setting-Knowledge and attitudes held by mental health professionals. Psychiatry Res 2014;220:1007-11.

213 Seo MK, Kim SH, Rhee M. Coercion in psychiatric care: can paternalism justify coercion? Int J Soc Psychiatry 2013;59:217-23.

214 Lovell A, Smith D, Johnson P. A qualitative investigation into nurses' perceptions of factors influencing staff injuries sustained during physical interventions employed in response to service user violence within one secure learning disability service. J Clin Nurs 2015;24:1926-35.

215 Tateno M, Sugiura K, Uehara K, et al. Attitude of young psychiatrists toward coercive measures in psychiatry: a case vignette study in Japan. Int J Ment Health Syst 2009;3:20.

216 Elmer T, Rabenschlag F, Schori D, et al. Informal coercion as a neglected form of communication in psychiatric settings in Germany and Switzerland. Psychiatry Res 2018;262:400-6.

217 Gustafsson N, Salzmann-Erikson M. Effect of complex working conditions on nurses who exert coercive measures in forensic psychiatric care. J Psychosoc Nurs Ment Health Serv 2016;54:37-43

218 Jalil R, Huber JW, Sixsmith J, et al. Mental health nurses' emotions, exposure to patient aggression, attitudes to and use of coercive measures: cross sectional questionnaire survey. Int J Nurs Stud 2017;75:130-8.

219 Martello M, Doronina O, Perillo A, et al. Nurses' Perceptions of Engaging With Patients to Reduce Restrictive Practices in an Inpatient Psychiatric Unit. Health Care Manag 2018:37:342-53.

220 McKeown M, Thomson G, Scholes A, et al. "Catching your tail and firefighting": The impact of staffing levels on restraint minimization efforts. J Psychiatr Ment Health Nurs 2019;26:131-41.
221 Molewijk B, Kok A, Husum T, et al. Staff's normative attitudes towards coercion: the role of moral doubt and professional context-a cross-sectional survey study. BMC Med Ethics 2017;18.

222 Raveesh BN, Pathare S, Noorthoorn EO, et al. Staff and caregiver attitude to coercion in India. Indian J Psychiatry 2016;58:221-9.

223 Georgieva I, Mulder CL, Wierdsma A. Patients' preference and experiences of forced medication and seclusion. Psychiatr $Q$ 2012;83:1-13

224 Haw C, Stubbs J, Bickle A, et al. Coercive treatments in forensic psychiatry: a study of patients' experiences and preferences. $J$ Forens Psychiatry Psychol 2011;22:564-85.

225 Sequeira H, Halstead S. "Is it meant to hurt, is it?" Management of violence in women with developmental disabilities. Violence against women 2001;7:462-76.

226 Sustere E, Tarpey E. Least restrictive practice: its role in patient independence and recovery. J Forens Psychiatry Psychol 2019;30:614-29.

227 Larsen IB, Terkelsen TB. Coercion in a locked psychiatric ward: perspectives of patients and staff. Nurs Ethics 2014;21:426-36.

228 Whittington $\mathrm{R}$, Bowers $\mathrm{L}$, Nolan $\mathrm{P}$, et al. Approval ratings of inpatient coercive interventions in a national sample of mental health service users and staff in England. Psychiatr Serv 2009;60:792-8

229 Reisch T, Beeri S, Klein G, et al. Comparing attitudes to containment measures of patients, health care professionals and next of kin. Front Psychiatry 2018;9.

230 Rippon D, Reid K, Kay G. Views on restrictive practices on young people in psychiatric wards. Nursing Times 2018:114:24-8.

231 Ryan CJ, Bowers L. Coercive manoeuvres in a psychiatric intensive care unit. J Psychiatr Ment Health Nurs 2005;12:695-702.

232 Johnston MS, Kilty JM. "It's for their own good": Techniques of neutralization and security guard violence against psychiatric patients. Punishment \& Society 2016:18:177-97.

233 Mackay I, Paterson B, Cassells C. Constant or special observations of inpatients presenting a risk of aggression or violence: nurses' perceptions of the rules of engagement. J Psychiatr Ment Health Nurs 2005;12:464-71.

234 Delaney KR, Johnson ME. Keeping the unit safe: Mapping psychiatric nursing skills. J Am Psychiatr Nurses Assoc 2006;12:198-207.

235 Happell B, Koehn S. Seclusion as a necessary intervention: the relationship between burnout, job satisfaction and therapeutic optimism and Justification for the use of seclusion. $J$ Adv Nurs 2011;67:1222-31.

236 Johnson ME, Delaney KR. Keeping the unit safe: a grounded theory study. J Am Psychiatr Nurses Assoc 2006;12:13-21.

237 Jonker EJ, Goossens PJJ, Steenhuis IHM, et al. Patient aggression in clinical psychiatry: perceptions of mental health nurses. $J$ Psychiatr Ment Health Nurs 2008;15:492-9.

238 Langan C, McDonald C. Daytime night attire as a therapeutic intervention in an acute adult psychiatric in-patient unit. Psychiatric Bulletin 2008;32:221-4

239 Maguire T, Daffern M, Martin T. Exploring nurses' and patients' perspectives of limit setting in a forensic mental health setting. Int $J$ Ment Health Nurs 2014;23:153-60.

240 Salzmann-Erikson M, Lützén K, Ivarsson A-B, et al. The core characteristics and nursing care activities in psychiatric intensive care units in Sweden. Int J Ment Health Nurs 2008;17:98-107.

241 Millar R, Sands N. 'He did what? Well, that wasn't handed over!' Communicating risk in mental health. J Psychiatr Ment Health Nurs 2013;20:345-54.

242 Sjöstrand M, Sandman L, Karlsson P, et al. Ethical deliberations about involuntary treatment: interviews with Swedish psychiatrists. BMC Med Ethics 2015;16:37.

243 Woods P. Risk assessment and management approaches on mental health units. J Psychiatr Ment Health Nurs 2013;20:807-13.

244 Cowan D, Brunero S, Luo X, et al. Developing a guideline for structured content and process in mental health nursing handover. Int J Ment Health Nurs 2018;27:429-39.

245 Cullen SW, Nath SB, Marcus SC. Toward understanding errors in inpatient psychiatry: a qualitative inquiry. Psychiatr $Q$ 2010;81:197-205.

246 Gifford ML, Anderson JE. Barriers and motivating factors in reporting incidents of assault in mental health care. J Am Psychiatr Nurses Assoc 2010;16:288-98.

247 Martin T, Daffern M. Clinician perceptions of personal safety and confidence to manage inpatient aggression in a forensic psychiatric setting. J Psychiatr Ment Health Nurs 2006:13:90-9.

248 Mezey G, Hassell Y, Bartlett A. Safety of women in mixed-sex and single-sex medium secure units: staff and patient perceptions. $\mathrm{Br} J$ Psychiatry 2005;187:579-82. 
249 Brennan G, Flood C, Bowers L. Constraints and blocks to change and improvement on acute psychiatric wards - lessons from the City Nurses project. J Psychiatr Ment Health Nurs 2006;13:475-82.

250 Kuosmanen A, Tiihonen J, Repo-Tiihonen E, et al. Changes in patient safety culture: a patient safety intervention for Finnish forensic psychiatric hospital staff. J Nurs Manag 2019;27:848-57.

251 Lavelle M, Attoe C, Tritschler C, et al. Managing medical emergencies in mental health settings using an interprofessional in-situ simulation training programme: a mixed methods evaluation study. Nurse Educ Today 2017;59:103-9.

252 Bowers L, Simpson A, Eyres S, et al. Serious untoward incidents and their aftermath in acute inpatient psychiatry: the Tompkins acute ward study. Int J Ment Health Nurs 2006;15:226-34.

253 Gabrielsson S, Looi G-ME, Zingmark K, et al. Knowledge of the patient as decision-making power: staff members' perceptions of interprofessional collaboration in challenging situations in psychiatric inpatient care. Scand J Caring Sci 2014;28:784-92.

254 Ward L. Ready, aim fire! mental health nurses under siege in acute inpatient facilities. Issues Ment Health Nurs 2013;34:281-7.

255 Ryan P, Anczewska M, Laijarvi H, et al. Demographic and situational variations in levels of burnout in European mental health services: a comparative study. Diversity Health Soc Care 2007:4:101-12.

256 Nathan R, Brown A, Redhead K, et al. Staff responses to the therapeutic environment: a prospective study comparing burnout among nurses working on male and female wards in a medium secure unit. J Forens Psychiatry Psychol 2007;18:342-52.

257 Vlayen Aet al. A nationwide Hospital survey on patient safety culture in Belgian hospitals: setting priorities at the Launch of a 5-year patient safety plan. BMJ Publishing Group Ltd 2012.

258 Ajalli Aet al. Explanation of patient safety provided by nurses in inpatient psychiatric wards in Iran: a qualitative study. Iranian Journal of Psychiatry and Behavioral Sciences 2018;12.

259 Wood D, Pistrang N. A safe place? service users' experiences of an acute mental health ward. J Community Appl Soc Psychol 2004;14:16-28.

260 Jones J, NOLAN P, BOWERS L, et al. Psychiatric wards: places of safety? J Psychiatr Ment Health Nurs 2010;17:124-30.

261 Ireland CA, Ireland JL, Jones NS, et al. Predicting security incidents in high secure male psychiatric care. Int J Law Psychiatry 2019;64:40-52.

262 Pelto-Piri V, Wallsten T, Hylén U, et al. Feeling safe or unsafe in psychiatric inpatient care, a hospital-based qualitative interview study with inpatients in Sweden. Int J Ment Health Syst 2019;13:23

263 Haines A, Brown A, McCabe R, et al. Factors impacting perceived safety among staff working on mental health wards. BJPsych Open 2017;3:204-11.

264 Kanerva A, Kivinen T, Lammintakanen J. Communication elements supporting patient safety in psychiatric inpatient care. J Psychiatr Ment Health Nurs 2015;22:298-305.

265 Kuosmanen A, Tiihonen J, Repo-Tiihonen E, et al. Patient safety culture in two Finnish state-run forensic psychiatric hospitals. $J$ Forensic Nurs 2013:9:207-16.

266 Wu J-C, Tung T-H, Chen PY, et al. Determinants of workplace violence against clinical physicians in hospitals. $J$ Occup Health 2015;57:540-7.

267 Kanerva A, Lammintakanen J, Kivinen T. Nursing staff's perceptions of patient safety in psychiatric inpatient care. Perspect Psychiatr Care 2016;52:25-31.

268 Stead K, Kumar S, Schultz TJ, et al. Teams communicating through STEPPS. Medical Journal of Australia 2009;190:S128-32.

269 Mahoney JS, Ellis TE, Garland G, et al. Supporting a psychiatric hospital culture of safety. J Am Psychiatr Nurses Assoc 2012:18:299-306.

270 Higgins N, Meehan T, Dart N, et al. Implementation of the Safewards model in public mental health facilities: a qualitative evaluation of staff perceptions. Int J Nurs Stud 2018;88:114-20.

271 Bowers L, Gournay K, Duffy D. Suicide and self-harm in inpatient psychiatric units: a national survey of observation policies. J Adv Nurs 2000;32:437-44.

272 O'Brien L, Cole R. Mental health nursing practice in acute psychiatric close-observation areas. Int J Ment Health Nurs 2004;13:89-99.

273 Stein WM. The use of discharge risk assessment tools in general psychiatric services in the UK. J Psychiatr Ment Health Nurs 2002;9:713-24.

274 Stübner S, GROB G, Nedopil N. Inpatient risk management with mentally ill offenders: results of a survey on clinical decision-making about easing restrictions. Criminal Behaviour and Mental Health 2006;16:111-23.
275 O'Neill C, Heffernan P, Goggins R, et al. Long-Stay forensic psychiatric inpatients in the Republic of ireland: aggregated needs assessment. Ir J Psychol Med 2003;20:119-25.

276 Rees P, Manthorpe J. Managers' and staff experiences of adult protection allegations in mental health and learning disability residential services: a qualitative study. Br J Soc Work 2010;40:513-29.

277 Koukia E, Giannouli E, Gonis N, et al. Security rules and banned items in psychiatric acute admission wards in Athens, Greece. Int $J$ Ment Health Nurs 2010;19:428-36.

278 Silvana S, Laura F, Ursula DF, et al. Ergonomics in the psychiatric ward towards workers or patients? Work 2012;41 Suppl 1:1832-5.

279 True G, Frasso R, Cullen SW, et al. Adverse events in Veterans Affairs inpatient psychiatric units: staff perspectives on contributing and protective factors. Gen Hosp Psychiatry 2017;48:65-71.

280 Vandewalle J, Malfait S, Eeckloo K, et al. Patient safety on psychiatric wards: a cross-sectional, multilevel study of factors influencing nurses' willingness to share power and responsibility with patients. Int J Ment Health Nurs 2018;27:877-90.

281 Gerace A, Muir-Cochrane E. Perceptions of nurses working with psychiatric consumers regarding the elimination of seclusion and restraint in psychiatric inpatient settings and emergency departments: an Australian survey. Int J Ment Health Nurs 2019;28:209-25.

282 Vahidi M, Ebrahimi H, Areshtanab HN, et al. Therapeutic relationships and safety of care in Iranian psychiatric inpatient units. Issues Ment Health Nurs 2018;39:967-76.

283 Holth F, Walby F, Røstbakken T, et al. Extreme challenges: psychiatric inpatients with severe self-harming behavior in Norway: a national screening investigation. Nord J Psychiatry 2018;72:605-12.

284 de Jonghe-Rouleau AP, Pot AM, de Jonghe JFM. Self-Injurious behaviour in nursing home residents with dementia. Int $J$ Geriatr Psychiatry 2005;20:651-7.

285 Sansone RA, McLean JS, Wiederman MW. The relationship between medically self-sabotaging behaviors and borderline personality disorder among psychiatric inpatients. Prim Care Companion J Clin Psychiatry 2008;10:448-52.

286 Gough K, Hawkins A. Staff attitudes to Self-harm and its management in a forensic psychiatric service. The British Journal of Forensic Practice 2000;2:22-8.

287 O'Donovan A. Pragmatism rules: the intervention and prevention strategies used by psychiatric nurses working with nonsuicidal self-harming individuals. J Psychiatr Ment Health Nurs 2007; 14:64-71.

288 Tofthagen R, Talseth A-G, Fagerström L. Mental Health Nurses' Experiences of Caring for Patients Suffering from Self-Harm. Nurs Res Pract 2014:2014:1-10.

289 Lundegaard Mattson Åse, Binder P-E, Mattson L. A qualitative exploration of how health care workers in an inpatient setting in Norway experience working with patients who self-injure. Nordic Psychology 2012;64:272-90.

290 Thomas JB, Haslam CO. How people who self-harm negotiate the inpatient environment: the mental healthcare workers perspective. Journal of Psychiatric \& Mental Health Nursing (John Wiley \& Sons, Inc 2017;24:480-90.

291 Shaw DG, Sandy PT. Mental health nurses' attitudes toward selfharm: Curricular implications. Health Sa Gesondheid 2016;21.

292 Sandy PT. The use of observation on patients who self-harm: Lessons from a learning disability service. Health Sa Gesondheid 2016;21.

293 James K, Samuels I, Moran P, et al. Harm reduction as a strategy for supporting people who self-harm on mental health wards: the views and experiences of practitioners. J Affect Disord 2017;214:67-73.

294 Brown J, Beail N. Self-Harm among people with intellectual disabilities living in secure service provision: a qualitative exploration. Journal of Applied Research in Intellectual Disabilities 2009;22:503-13.

295 Lindgren B-M, Aminoff C, Hällgren Graneheim U. Features of everyday life in psychiatric inpatient care for self-harming: an observational study of six women. Issues Ment Health Nurs 2015;36:82-8.

296 Weber MT. Triggers for self-abuse: a qualitative study. Arch Psychiatr Nurs 2002;16:118-24.

297 Gibson J, Booth R, Davenport J, et al. Dialectical behaviour therapy-informed skills training for deliberate self-harm: a controlled trial with 3-month follow-up data. Behav Res Ther 2014;60:8-14.

298 Booth R, Keogh K, Doyle J, et al. Living through distress: a skills training group for reducing deliberate self-harm. Behav Cogn Psychother 2014;42:156-65. 
299 Bowers L, Whittington R, Nolan P, et al. Relationship between service ecology, special observation and self-harm during acute in-patient care: City-128 study. Br J Psychiatry 2008;193:395-401.

300 Kool N, van Meijel B, Koekkoek B, et al. Improving communication and practical skills in working with inpatients who self-harm: a pretest/post-test study of the effects of a training programme. BMC Psychiatry 2014;14:64.

301 Drew BL. No-suicide contracts to prevent suicidal behavior in inpatient psychiatric settings. Journal of the American Psychiatric Nurses Association 1999:5:23-8.

302 Sjöström N, Hetta J, Waern M. Sense of coherence and suicidality in suicide attempters: a prospective study. J Psychiatr Ment Health Nurs 2012;19:62-9.

303 Swogger MT, Van Orden KA, Conner KR. The relationship of outwardly directed aggression to suicidal ideation and suicide attempts across two high-risk samples. Psychol Violence 2014;4:184-95.

304 Hill RM, Hatkevich CE, Kazimi I, et al. The Columbia-Suicide severity rating scale: associations between interrupted, aborted, and actual suicide attempts among adolescent inpatients. Psychiatry Res 2017;255:338-40.

305 Inoue K, Kawanishi C, Otsuka K, et al. A large-scale survey of inpatient suicides: comparison between medical and psychiatric settings. Psychiatry Res 2017;250:155-8.

306 Ellis TE, Green KL, Allen JG, et al. Collaborative assessment and management of suicidality in an inpatient setting: results of a pilot study. Psychotherapy 2012;49:72-80.

307 Ellis TE, Rufino KA, Allen JG, et al. Impact of a Suicide-Specific intervention within inpatient psychiatric care: the collaborative assessment and management of suicidality. Suicide Life Threat Behav 2015;45:556-66.

308 Awenat YF, Peters S, Gooding PA, et al. A qualitative analysis of suicidal psychiatric inpatients views and expectations of psychological therapy to counter suicidal thoughts, acts and deaths. BMC Psychiatry 2018;18:334

309 Cleary M, Jordan R, Horsfall J, et al. Suicidal patients and special observation. J Psychiatr Ment Health Nurs 1999;6:461-7.

310 Takahashi C, Chida F, Nakamura H, et al. The impact of inpatient suicide on psychiatric nurses and their need for support. BMC Psychiatry 2011:11:38

311 Vråle GB, Steen E. The dynamics between structure and flexibility in constant observation of psychiatric inpatients with suicidal ideation. J Psychiatr Ment Health Nurs 2005;12:513-8.

312 Vandewalle J, Beeckman D, Van Hecke A, et al. 'Promoting and preserving safety and a life-oriented perspective': A qualitative study of nurses' interactions with patients experiencing suicidal ideation. Int J Ment Health Nurs 2019;28:1122-34.

313 Davis SE, Williams IS, Hays LW. Psychiatric inpatients' perceptions of written no-suicide agreements: an exploratory study. Suicide Life Threat Behav 2002;32:51-66.

314 Esposito-Smythers C, McClung TJ, Fairlie AM. Adolescent perceptions of a suicide prevention group on an inpatient unit. Archives of Suicide Research 2006;10:265-75.

315 Sun F-K, Long A, Boore J, et al. Nursing people who are suicidal on psychiatric wards in Taiwan: action/interaction strategies. $J$ Psychiatr Ment Health Nurs 2005;12:275-82.

316 Sun F-K, Long A, Boore J, et al. Patients and nurses' perceptions of ward environmental factors and support systems in the care of suicidal patients. J Clin Nurs 2006;15:83-92.

317 Pfeiffer PNet al. Development and pilot study of a suicide prevention intervention delivered by peer support specialists. Psychological Services 2018.

318 Caspi E. Does self-neglect occur among older adults with dementia when unsupervised in assisted living? an exploratory, observational study. J Elder Abuse Negl 2014;26:123-49.

319 Bowers L, HAGLUND K, MUIR-COCHRANE E, et al. Locked doors: a survey of patients, staff and visitors. J Psychiatr Ment Health Nurs 2010;17:873-80.

320 Haglund K, von Essen L. Locked entrance doors at psychiatric wards - advantages and disadvantages according to voluntarily admitted patients. Nord J Psychiatry 2005;59:511-5.

321 Muir-Cochrane E, van der Merwe M, Nijman H, et al. Investigation into the acceptability of door locking to staff, patients, and visitors on acute psychiatric wards. Int $J$ Ment Health Nurs 2012;21:41-9.

322 Cowman S, Bowers L. Safety and security in acute admission psychiatric wards in Ireland and London: a comparative study. $J$ Clin Nurs 2009;18:1346-53.

323 Simpson A, Bowers L, Haglund K, et al. The relationship between substance use and exit security on psychiatric wards. J Adv Nurs 2011:67:519-30.
324 Kalagi J, Otte I, Vollmann J, et al. Requirements for the implementation of open door policies in acute psychiatry from a mental health professionals' and patients' view: a qualitative interview study. BMC Psychiatry 2018:18:304.

325 Fletcher J, Hamilton B, Kinner S, et al. Working towards least restrictive environments in acute mental health wards in the context of locked door policy and practice. Int J Ment Health Nurs 2019;28:538-50.

326 van der Schaaf PS, Dusseldorp E, Keuning FM, et al. Impact of the physical environment of psychiatric wards on the use of seclusion. British Journal of Psychiatry 2013;202:142-9.

327 Verbeek H, Zwakhalen SMG, van Rossum E, et al. Effects of smallscale, home-like facilities in dementia care on residents' behavior, and use of physical restraints and psychotropic drugs: a quasiexperimental study. International Psychogeriatrics 2014;26:657-68.

328 Curtis S, Gesler W, Wood V, et al. Compassionate containment? balancing technical safety and therapy in the design of psychiatric wards. Soc Sci Med 2013;97:201-9.

329 Dreyfus S, Phillipson L, Fleming R. Staff and family attitudes to fences as a means of detaining people with dementia in residential aged care settings: the tension between physical and emotional safety. Australian Journal of Social Issues 2018;53:107-22.

330 Bayramzadeh S. An assessment of levels of safety in psychiatric units. HERD 2017:10:66-80.

331 Bellantonio S, Kenny AM, Fortinsky RH, et al. Efficacy of a geriatrics team intervention for residents in Dementia-Specific assisted living facilities: effect on unanticipated transitions. J Am Geriatr Soc 2008;56:523-8.

332 Chandler G. From traditional inpatient to trauma-informed treatment: transferring control from staff to patient. J Am Psychiatr Nurses Assoc 2008;14:363-71.

333 Wilkes L, Fleming A, Wilkes BL, et al. Environmental approach to reducing agitation in older persons with dementia in a nursing home. Australas J Ageing 2005;24:141-5.

334 Gebhardt RP, Steinert T. Should severely disturbed psychiatric patients be distributed or concentrated in specialized wards? an empirical study on the effects of hospital organization on ward atmosphere, aggressive behavior, and sexual molestation. Eur Psychiatry 1999;14:291-7.

335 Stolker JJ, Nijman HLI, Zwanikken P-H. Are patients' views on seclusion associated with lack of privacy in the ward? Arch Psychiatr Nurs 2006;20:282-7.

336 Kulkarni J, Gavrilidis E, Lee S, et al. Establishing female-only areas in psychiatry wards to improve safety and quality of care for women. Australasian Psychiatry 2014;22:551-6.

337 Bowers L, Crowder M. Nursing staff numbers and their relationship to conflict and containment rates on psychiatric wards - A cross sectional time series poisson regression study. Int J Nurs Stud 2012;49:15-20.

338 Triplett P, Dearholt S, Cooper M, et al. The milieu manager: a nursing staffing strategy to reduce observer use in the acute psychiatric inpatient setting. J Am Psychiatr Nurses Assoc 2017;23:422-30.

339 Hunt IM, Windfuhr K, Shaw J, et al. Ligature points and ligature types used by psychiatric inpatients who die by hanging: a national study. Crisis 2012;33:87-94.

340 Ruzić K, Francisković T, Suković Z, et al. Aggresiveness in institutionalised schizophrenic patients and the selection of antipsychotics. Coll Antropol 2011;35:265-9.

341 Rodríguez-Leal CM, López-Lunar E, Carrascosa-Bernáldez JM, et al. Electrocardiographic surveillance in a psychiatric institution: avoiding iatrogenic cardiovascular death. Int J Psychiatry Clin Pract 2017;21:64-6.

342 Seemüller F, Riedel M, Obermeier M, et al. The controversial link between antidepressants and suicidality risks in adults: data from a naturalistic study on a large sample of in-patients with a major depressive episode. Int. J. Neuropsychopharm. 2009;12:181-9.

343 Haw C, Stubbs J, Dickens GL. Barriers to the reporting of medication administration errors and near misses: an interview study of nurses at a psychiatric hospital. J Psychiatr Ment Health Nurs 2014;21:n/a-805.

344 Soerensen ALet al. The medication process in a psychiatric Hospital: are errors a potential threat to patient safety? Risk management and healthcare policy 2013;6:23.

345 Keers RN, Plácido M, Bennett K, et al. What causes medication administration errors in a mental health hospital? A qualitative study with nursing staff. PLoS One 2018;13:e0206233.

346 Bademli K, Buldukoglu K. Oral medication management in inpatient psychiatric care in turkey. J Psychiatr Ment Health Nurs 2009:16:355-62. 
347 Prins MC, Drenth-van Maanen AC, Kok RM, et al. Use of a structured medication history to establish medication use at admission to an old age psychiatric clinic: a prospective observational study. CNS Drugs 2013;27:963-9.

348 Xie N, Kalia K, Strudwick G, et al. Understanding mental health nurses' perceptions of barcode medication administration: a qualitative descriptive study. Issues Ment Health Nurs 2019;40:326-34.

349 Strudwick G, Clark C, McBride B, et al. Thank you for asking: exploring patient perceptions of barcode medication administration identification practices in inpatient mental health settings. Int $\mathrm{J} \mathrm{Med}$ Inform 2017; 105:31-7.

350 Cottney A, Innes J. Medication-administration errors in an urban mental health Hospital: a direct observation study. Int J Ment Health Nurs 2015;24:65-74.

351 Dickens G, Stubbs J, Haw C, Raw C. Delegation of medication administration: an exploratory study. Nursing Standard 2008;22:35-40.

352 Haw C, Stubbs J, Dickens G. An observational study of medication administration errors in old-age psychiatric inpatients. International Journal for Quality in Health Care 2007;19:210-6.

353 Cottney A. Improving the safety and efficiency of nurse medication rounds through the introduction of an automated dispensing cabinet. BMJ Open Quality 2014;3.

354 Dolan M, Kirwan H. Survey of staff perceptions of illicit drug use among patients in a medium secure unit. Psychiatric Bulletin 2001;25:14-17.

355 Hughes E, Bressington D, Sharratt K, et al. Novel psychoactive substance use by mental health service consumers: an online survey of inpatient health professionals' views and experiences. Adv Dual Diagn 2018;11:30-9.

356 Gonzalez-Pinto A, De Azua SR. S.2.04 adherence to treatment in bipolar disorders. European Neuropsychopharmacology 2011:21:S108-9.

357 Meehan T, Morrison P, McDougall S. Absconding behaviour: an exploratory investigation in an acute inpatient unit. Aust $N Z J$ Psychiatry 1999;33:533-7.

358 Muir-Cochrane E, Oster C, Grotto J, et al. The inpatient psychiatric unit as both a safe and unsafe place: implications for absconding Int J Ment Health Nurs 2013;22:304-12.

359 Nurjannah I, FitzGerald M, Foster K. Patients' experiences of absconding from a psychiatric setting in Indonesia. Int $J$ Ment Health Nurs 2009;18:326-35.

360 Grotto J, Gerace A, O'Kane D, et al. Risk assessment and absconding: perceptions, understandings and responses of mental health nurses. J Clin Nurs 2015;24:855-65.

361 Bowers L, Alexander J, Gaskell C. A trial of an anti-absconding intervention in acute psychiatric wards. J Psychiatr Ment Health Nurs 2003:10:410-6.

362 Simpson AIF, Penney SR, Fernane S, et al. The impact of structured decision making on absconding by forensic psychiatric patients: results from an A-B design study. BMC Psychiatry 2015;15:103.

363 Algase DL, Beattie ERA, Antonakos C, et al. Wandering and the physical environment. Am J Alzheimers Dis Other Demen 2010;25:340-6.

364 Colombo M, Vitali S, Cairati M, et al. Wanderers: features, findings, issues. Arch Gerontol Geriatr 2001;33:99-106.

365 Hunt IM, Clements C, Saini P, et al. Suicide after absconding from inpatient care in England: an exploration of mental health professionals' experiences. Journal of Mental Health 2016;25:245-53.

366 Hunt IM, Windfuhr K, Swinson N, et al. Suicide amongst psychiatric in-patients who abscond from the ward: a national clinical survey. BMC Psychiatry 2010;10:14

367 Nijman Het al. Door locking and exit security measures on acute psychiatric admission wards. Journal of Psychiatric and Mental Health Nursing 2011;18): :614-21.

368 Whaley AL. A two-stage method for the study of cultural bias in the diagnosis of schizophrenia in African Americans. Journal of Black Psychology 2004;30:167-86.

369 Whaley AL. Cultural mistrust and the clinical diagnosis of paranoid schizophrenia in African American patients. J Psychopathol Behav Assess 2001;23:93-100.

370 Green R, Shelly C, Gibb J, et al. Implementing seclusion in forensic mental health care: a qualitative study of staff decision making. Arch Psychiatr Nurs 2018;32:764-8.

371 Koukia E, Madianos MG, Katostaras T. "On the spot" interventions by mental health nurses in inpatient psychiatric wards in Greece. Issues Ment Health Nurs 2009:30:327-36.
372 Lindsey PL. Psychiatric nurses' decision to restrain: the association between empowerment and individual factors. Journal of psychosocial nursing and mental health services 2009;47:41-9.

373 Mann-Poll PS, Smit A, de Vries WJ, et al. Factors contributing to mental health professionals' decision to use seclusion. Psychiatric Services 2011;62:498-503.

374 Marangos-Frost S, Wells D. Psychiatric nurses' thoughts and feelings about restraint use: a decision dilemma. J Adv Nurs 2000;31:362-9.

375 Brown B, Rakow T. Understanding clinicians' use of cues when assessing the future risk of violence: a clinical judgement analysis in the psychiatric setting. Clin Psychol Psychother 2016;23:125-41.

376 Fuller J, Cowan J. Risk assessment in a multi-disciplinary forensic setting: clinical judgement revisited. The Journal of Forensic Psychiatry 1999;10:276-89.

377 Abraham S. Managing patient falls in psychiatric inpatient units. Health Care Manag 2016;35:21-7.

378 Fonad E, Emami A, Wahlin T-BR, et al. Falls in somatic and dementia wards at community care units. Scand $\mathrm{J}$ Caring $\mathrm{Sci}$ 2009;23:2-10.

379 Tängman S, Eriksson S, Gustafson Y, et al. Precipitating factors for falls among patients with dementia on a psychogeriatric ward. International Psychogeriatrics 2010;22:641-9.

380 Garfinkel D, Radomislsky Z, Jamal S, et al. High efficacy for hip protectors in the prevention of hip fractures among elderly people with dementia. J Am Med Dir Assoc 2008;9:313-8.

381 Holmes Det al. An evaluation of a monitoring system intervention: falls, injuries, and affect in nursing homes. Clinical nursing research 2007;16:317-35.

382 Powell-Cope G, Quigley P, Besterman-Dahan K, et al. A qualitative understanding of patient falls in inpatient mental health units. $J$ Am Psychiatr Nurses Assoc 2014;20:328-39.

$383 \mathrm{Li}$ PHet al. Infection preventionists' challenges in psychiatric clinical settings. American Journal of Infection Control 2019;47:123-7.

384 D'Lima D, Crawford MJ, Darzi A, et al. Patient safety and quality of care in mental health: a world of its own? BJPsych Bulletin 2017;41:241-3.

385 Sakinofsky I. Preventing suicide among inpatients. The Canadian Journal of Psychiatry 2014;59:131-40.

386 Leape L, Berwick D, Clancy C, et al. Transforming healthcare: a safety imperative. Qual Saf Health Care 2009;18:424-8.

387 Gandhi TK, Kaplan GS, Leape L, et al. Transforming concepts in patient safety: a progress report. BMJ Qual Saf 2018;27:1019-26.

388 Schwappach DLB. Review: engaging patients as vigilant partners in safety: a systematic review. Med Care Res Rev 2010;67:119-48.

389 Davis RE, Sevdalis N, Vincent CA. Patient involvement in patient safety: how willing are patients to participate? BMJ Qual Saf 2011;20:108-14.

390 Institute, N.P.S.F.s.L.L.. Safety is personal: partnering with patients and families for the safest care. Moston: MA.: National Patient Safety Foundation, 2014

391 Providers N. Funding for mental health at a local level: Unpicking the variation. NHS Providers 2016

392 Prince M, Patel V, Saxena S, et al. No health without mental health. The Lancet 2007;370:859-77.

393 Unsworth J, McKeever M, Kelleher M. Recognition of physical deterioration in patients with mental health problems: the role of simulation in knowledge and skill development. $J$ Psychiatr Ment Health Nurs 2012:19:536-45.

394 Cooper JB, Gaba DM, Liang B, et al. The National patient safety Foundation agenda for research and development in patient safety. MedGenMed 2000;2:E38.

395 Institute of Medicine Committee on Quality of Health Care in, A. in To Err is Human: Building a Safer Health System, L.T. Kohn, J.M. Corrigan, and M.S. Donaldson, Editors. 2000, National Academies Press (US) Copyright 2000 by the National Academy of Sciences. All rights reserved. Washington (DC.

396 Emanuel L, Berwick D, Conway J, et al. Advances in Patient Safety: New Directions and Alternative Approaches (Vol. 1: Assessment). In: What exactly is patient safety? Bethesda MD, USA: U.S. Nationa Library of Medicine, 2008.

397 Hox JJ, Boeije HR. Data collection, primary versus secondary 2005.

398 Appleby L, Shaw J, Amos T. National confidential inquiry into suicide and homicide by people with mental illness. Br J Psychiatry 1997;170:101-2.

399 Elliott JH, Turner T, Clavisi O, et al. Living systematic reviews: an emerging opportunity to narrow the evidence-practice gap. PLoS Med 2014;11:e1001603.

400 Long L. Routine piloting in systematic reviews - a modified approach? Syst Rev 2014;3:77. 
401 Landis JR, Koch GG. The measurement of observer agreement for categorical data. Biometrics 1977;33:159-74.

402 Gopalakrishnan S, Ganeshkumar P. Systematic reviews and metaanalysis: understanding the best evidence in primary healthcare. $J$ Family Med Prim Care 2013;2.
403 Dewa LH, Murray K, Thibaut B, et al. Identifying research priorities for patient safety in mental health: an international expert Delphi study. BMJ Open 2018;8:e021361. 